\title{
Experimental deformation and recrystallization of olivine - processes and timescales of damage healing during postseismic relaxation at mantle depths
}

\author{
C. A. Trepmann ${ }^{1}$, J. Renner ${ }^{2}$, and A. Druiventak ${ }^{2}$ \\ ${ }^{1}$ Department for Earth and Environmental Sciences, Ludwig-Maximilians-Universität München, Germany \\ ${ }^{2}$ Institute for Geology, Mineralogy, and Geophysics, Ruhr-Universität Bochum, Germany \\ Correspondence to: C. A. Trepmann (claudia.trepmann@lmu.de)
}

Received: 20 March 2013 - Published in Solid Earth Discuss.: 17 April 2013

Revised: 28 August 2013 - Accepted: 9 September 2013 - Published: 11 November 2013

\begin{abstract}
Experiments comprising sequences of deformation (at 300 or $600^{\circ} \mathrm{C}$ ) and annealing at varying temperature $\left(700\right.$ to $1100^{\circ} \mathrm{C}$ ), time (up to $144 \mathrm{~h}$ ) and stress (up to $1.5 \mathrm{GPa}$ ) were carried out in a Griggs-type apparatus on natural olivine-rich peridotite samples to simulate deformation and recrystallization processes in deep shear zones that reach mantle depth as continuations of seismically active faults. The resulting olivine microfabrics were analysed by polarization and electron microscopy (SEM/EBSD, TEM). Core-and-mantle-like microstructures are the predominant result of our experiments simulating rapid stress relaxation (without or with minor creep) after a high-stress deformation event: porphyroclasts (>100 $\mu \mathrm{m}$ ) are surrounded by new grains comprising fragments and recrystallized grains with a wide range in size (2 to $40 \mu \mathrm{m})$. Areas with small grains $(\leq 10 \mu \mathrm{m})$ trace former high-strain zones generated during initial high-stress deformation even after annealing at a temperature of $1100^{\circ} \mathrm{C}$ for $70 \mathrm{~h}$. A weak crystallographic preferred orientation (CPO) of new olivine grains is related to the orientation of the original host crystals but appears unrelated to the strain field. Based on these findings, we propose that olivine microstructures in natural shear-zone peridotites with a large range in grain size, localized fine-grained zones, and a weak CPO not related to the strain field are diagnostic for a sequence of high-stress deformation followed by recrystallization at low stresses, as to be expected in areas of seismic activity. We extended the classic Avrami-kinetics equation by accounting for time-dependent growth kinetics and constrained the involved parameters relying on our results and previous studies devoted to the kinetics of defect pro-
\end{abstract}

cesses in olivine. Extrapolation to natural conditions suggests that the observed characteristic microstructure may develop within as little as tens of years and less than ten thousands of years. These recrystallization microstructures have a great diagnostic potential for past seismic activity because they are expected to be stable over geological timescales, since driving forces for further modification are not sufficient to erase the characteristic heterogeneities.

\section{Introduction}

In the tectonic environment of subduction zones, shear zones can reach down to mantle depth as continuation of seismically active fault zones, as for example observed for the Sumatra earthquake in 2004 that caused the infamous tsunami (Singh et al., 2008; Dessa et al., 2009). The macroscale time-dependent rheology of such shear zones is controlled by nano- to micro-scale deformation and recrystallization processes in the affected upper mantle rocks (i.e., peridotites). What are these processes and what are their characteristic timescales for damage healing? These questions can be addressed by experimentally studying deformation and recrystallization processes during characteristic stress sequences. Large earthquakes generate short-term high strain rates and stresses at depth below the seismogenic zone and below the long-term lithospheric brittle-ductile transition, causing transiently brittle mechanisms at depth where at lower stress the material shows ductile behaviour (e.g., Sibson, 1980; Scholz, 2002; Ellis and Stöckhert, 2004; Nüchter 
and Ellis, 2010). This temporal change in rheology is reflected by

1. seismological observations: maximum hypocenter depths are initially larger than that of the preceding background seismicity and then decrease gradually with time back to the original level (e.g., Ben-Zion and Lyakhovsky, 2006; Ben-Zion, 2008) and aftershocks following large earthquakes occur transiently at larger depth than the main event (e.g., Schaff et al., 2002; Rolandone et al., 2004).

2. the microstructural record of deformation at high stress and recrystallization at lower stress from exhumed metamorphic rocks (e.g. Küster and Stöckhert, 1999; Trepmann and Stöckhert, 2001, 2002, 2003; Nüchter and Stöckhert, 2007; Birtel and Stöckhert, 2008; Matysiak and Trepmann, 2012).

Despite the important influence of rapidly changing stresses and strain rates on deformation and recrystallization in shear zones, these processes are commonly discussed from a perspective of long-lasting constant stress and strain-rate conditions (e.g., Platt and Behr, 2011a, b). The focus on deformation and recrystallization at such quasi-stationary conditions owes partly to the lack of diagnostic features in the geological record that can be used to assess whether recrystallization occurs continuously together with deformation (dynamic recrystallization) at relatively constant stresses or subsequently to high-stress deformation when stresses decrease and eventually become insufficient to maintain inelastic deformation (static recrystallization). Microstructures, formed at rapidly evolving conditions during coseismic loading and postseismic relaxation, superimpose each other and a prolonged thermal history of exhumed rocks causes a modification of the earlier features. Therefore, non-steady-state experiments at successively different stress conditions are needed to identify characteristic overprinting microfabrics and the relevant timescales of their evolution. Such experiments, designed to simulate the natural stress history during coseismic loading and postseismic relaxation, were performed on natural vein quartz (Trepmann et al., 2007; Trepmann and Stöckhert, 2013) and on natural peridotites (Druiventak et al., 2012). Olivine in peridotites experimentally deformed at low temperatures and high stresses reveals specific microstructures (Druiventak et al., 2011) that are modified by recovery and recrystallization to core-and-mantle-like microstructures during annealing at quasi-isostatic conditions (Druiventak et al., 2012). The experimentally derived core-and-mantle-like microstructures are strikingly similar to those from shear zone peridotites (Druiventak et al., 2012; Matysiak and Trepmann, 2012) often interpreted to be formed by continuous dynamic recrystallization during dislocation creep at relatively constant stresses.

The primary objectives of this experimental study are documenting the microfabric evolution and constraining the ki- netics parameters of static recrystallization of olivine after high-stress deformation. For this end, we carried out experiments comprising deformation and isostatic annealing ("kick and cook") at various temperatures and for different durations, simulating quasi-instantaneous stress relaxation and a subsequent prolonged isothermal low-stress event. We aim at establishing relations between deformation conditions, annealing temperature, and annealing time on the one hand and area percentage, grain size, and crystallographic characteristics of recrystallized olivine on the other. In addition, we want to find out to what extent complex stress histories as likely occurring in natural situations affect the characteristic microfabrics and how the modified microstructure affects rock strength. We therefore (a) simulate creep at low stresses during recrystallization ("kick and creep") and (b) repeat deformation after a first deformation and isostatic annealing ("kick-cook-kick"). The microstructural findings from our experiments and the inferred kinetics parameters are used to discuss the time-dependent rheology and damage healing processes in shear zones that occur at mantle depths as continuations of seismically active faults.

\section{Characteristics of the experimental approach}

\subsection{Experimental protocol}

The Griggs-type apparatus, its sample assembly, and the sample material, a coarse-grained (grain size 0.2 to $1 \mathrm{~mm}$ ) peridotite (up to $90 \%$ olivine, orthopyroxene, chromite and chromium chlorite) from the Almklovdalen complex, Norway, have previously been described in detail (Druiventak et al., 2011, 2012). In this study, five suites of experiments were carried out with varying sequences of deformation and annealing.

1. To simulate instantaneous stress relaxation after highstress deformation, samples were deformed at temperatures of 300 and $600{ }^{\circ} \mathrm{C}$, at a confining pressure of $1 \mathrm{GPa}$. The strain rates varied between $3 \times 10^{-5}$ and $8 \times 10^{-5} \mathrm{~s}^{-1}$ (Table 1). After deformation, the axial piston was retracted and samples were heated at a constant rate of $5^{\circ} \mathrm{C} \mathrm{min}^{-1}$ to temperatures of 700 to $1100^{\circ} \mathrm{C}$. To avoid melting of the confining medium, the confining pressure was simultaneously increased at a constant rate to $2 \mathrm{GPa}$ and these conditions were held for ca. 16, 70 or $144 \mathrm{~h}$.

2. Two reference annealing experiments without preceding deformation ("cook", Table 1) were performed at a temperature of $1000^{\circ} \mathrm{C}$, a confining pressure of $2 \mathrm{GPa}$, and a duration of ca. $70 \mathrm{~h}$. One experiment (B9026) was performed in the Griggs-type apparatus and one (B9032) in a standard piston cylinder apparatus (Renner et al., 1997). 
Table 1. Mechanical data from the deformation and annealing experiments.

\begin{tabular}{|c|c|c|c|c|c|c|c|c|c|c|c|c|c|}
\hline \multirow[b]{3}{*}{ sample\# } & \multirow{2}{*}{\multicolumn{5}{|c|}{$\begin{array}{l}\text { High-stress deformation (“kick") } \\
\qquad p_{\mathrm{c}}=1 \mathrm{GPa}\end{array}$}} & \multirow{2}{*}{\multicolumn{8}{|c|}{$\begin{array}{l}\text { Quasi-static annealing (“cook") } \\
\qquad p_{\mathrm{c}}=2 \mathrm{GPa}\end{array}$}} \\
\hline & & & & & & & & & & & & & \\
\hline & $\begin{array}{l}T_{\mathrm{c}, \mathrm{def}} \\
{\left[{ }^{\circ} \mathrm{C}\right]}\end{array}$ & $\begin{array}{l}T_{\mathrm{m}, \mathrm{def}} \\
{\left[{ }^{\circ} \mathrm{C}\right]}\end{array}$ & $\begin{array}{l}\mathrm{SR} \\
{\left[10^{-5} \mathrm{~s}^{-1}\right]}\end{array}$ & $\begin{array}{l}\Delta \sigma_{\max } \\
{[\mathrm{GPa}]}\end{array}$ & $\begin{array}{l}\varepsilon_{\max } \\
{[\%]}\end{array}$ & $\begin{array}{l}T_{\mathrm{c}, \text { ann }} \\
{\left[{ }^{\circ} \mathrm{C}\right]}\end{array}$ & $\begin{array}{l}T_{\mathrm{m}, \text { ann }} \\
{\left[{ }^{\circ} \mathrm{C}\right]}\end{array}$ & $\begin{array}{l}t_{\mathrm{ann}} \\
{[\mathrm{h}]}\end{array}$ & $\begin{array}{l}A \\
{[\%]}\end{array}$ & $\begin{array}{l}d_{\exp } \\
{[\mu \mathrm{m}]}\end{array}$ & $\begin{array}{l}\text { std } \\
{[\mu \mathrm{m}]}\end{array}$ & $\begin{array}{l}d_{\max } \\
{[\mu \mathrm{m}]}\end{array}$ & $\begin{array}{l}\varepsilon_{\text {tot }} \\
{[\%]}\end{array}$ \\
\hline $\mathrm{KH} 17^{1}$ & 260 & 326 & 3.0 & 1.6 & 25 & & & & & & & & nd \\
\hline B9016 & 301 & 296 & 7.4 & 1.4 & 28 & & & & & & & & 33 \\
\hline B9027 & 301 & 298 & 6.6 & 1.1 & 19 & & & & & & & & 24 \\
\hline B $9001^{1,2}$ & 601 & 614 & 7.9 & 1.1 & 19 & & & & no anne & & & & 6 \\
\hline B9003 & 602 & 614 & 8.0 & 1.1 & 21 & & & & & & & & nd \\
\hline B $9009^{1,2}$ & 601 & 595 & 7.6 & 1.3 & 24 & & & & & & & & 26 \\
\hline B9030 & 602 & 584 & 7.4 & 1.1 & 16 & & & & & & & & 17 \\
\hline B9021 & 301 & 307 & 7.5 & 1.2 & 25 & 702 & 704 & 16.4 & 0.2 & 2.9 & 0.9 & 6.3 & 25 \\
\hline B9034 & 301 & 285 & 6.7 & 0.9 & 18 & 702 & 667 & 144.3 & 1.0 & 4.0 & 1.6 & 9.9 & 28 \\
\hline B9020 & 301 & 279 & 6.9 & 1.6 & 23 & 801 & 764 & 16.6 & 1.2 & 3.6 & 1.0 & 7.0 & 21 \\
\hline B9019 & 301 & 303 & 7.4 & 1.3 & 23 & 901 & 890 & 16.8 & 2.6 & 3.8 & 1.2 & 8.0 & 15 \\
\hline B9018 & 301 & 337 & 7.4 & 1.3 & 25 & 1001 & 858 & 16.2 & 5.1 & 3.9 & 1.5 & 11.6 & 30 \\
\hline B9017 & 301 & 300 & 7.4 & 1.4 & 27 & 1001 & 1011 & 69.2 & 12.6 & 5.2 & 2.7 & 23.1 & 25 \\
\hline B9028 & 301 & 298 & 7.0 & 1.6 & 22 & 1001 & 992 & 144.0 & 30.9 & 9.9 & 4.9 & 31.7 & 14 \\
\hline B $9007^{2}$ & 602 & nd & 8.0 & 1.0 & 18 & 702 & nd & 16.2 & 0.2 & 3.1 & 0.9 & 6.4 & 11 \\
\hline B9031 & 601 & 610 & 7.3 & 1.0 & 14 & 702 & 705 & 144.1 & 1.2 & 3.4 & 1.5 & 9.7 & 23 \\
\hline B9005 2 & 601 & 592 & 8.1 & 1.0 & 17 & 801 & 790 & 16.3 & 0.5 & 3.4 & 1.3 & 10.0 & 18 \\
\hline B9035 & 601 & 601 & 8.0 & 1.0 & 21 & 801 & 787 & 72.2 & 1.5 & 3.1 & 1.4 & 11.9 & 26 \\
\hline B9024 & 601 & 577 & 7.6 & 1.3 & 19 & 801 & 768 & 144.0 & 1.2 & 4.1 & 1.6 & 10.7 & 14 \\
\hline B $9004^{2}$ & 601 & 622 & 7.5 & 1.0 & 17 & 901 & 929 & 16.2 & 2.7 & 3.0 & 1.4 & 11.0 & 9 \\
\hline B9022 & 601 & 613 & 8.2 & 0.9 & 23 & 901 & 831 & 69.0 & 2.9 & 3.0 & 1.2 & 10.0 & 31 \\
\hline B9025 & 601 & 599 & 7.8 & 1.5 & 20 & 901 & 895 & 144.0 & 6.0 & 4.0 & 2.1 & 18.0 & 27 \\
\hline B $9006^{2}$ & 601 & 625 & 7.7 & 1.2 & 18 & 1001 & 1018 & 16.2 & 9.3 & 4.0 & 2.2 & 18.0 & 11 \\
\hline B9010 & 602 & 496 & 8.0 & 1.3 & 23 & 1001 & 1007 & 68.9 & 7.5 & 4.0 & 3.1 & 41.0 & 5 \\
\hline B9029 & 602 & 579 & 7.9 & 1.0 & 19 & 1001 & 961 & 143.9 & 18.7 & 5.0 & 3.5 & 26.0 & 29 \\
\hline B9036 & 601 & 618 & 7.9 & 1.0 & 15 & 1100 & 1089 & 69.3 & 26.7 & 5.0 & 5.1 & 42.0 & 26 \\
\hline B9026 & & & no deformat & & & 1000 & 1002 & 68.8 & 0.3 & 4.2 & 3.6 & 25.8 & 3 \\
\hline $\mathrm{B} 9032^{\mathrm{p}}$ & & & no deformat & & & 1001 & nd & 75.2 & $<0.1$ & 4.9 & 3.5 & 40.8 & 1 \\
\hline
\end{tabular}

$T_{\mathrm{c}, \text { def }}, T_{\mathrm{m} \text {,def }}, T_{\mathrm{c} \text {,ann }}$ and $T_{\mathrm{m} \text {,ann }}$ : temperature readings (not corrected for pressure) of the controlling and monitoring thermocouples during deformation and annealing, respectively. SR: strain rate; $\Delta \sigma_{\max }$ : maximum differential stress; $\varepsilon$ true: sum of elastic and inelastic strain derived from stress-strain curves; $t_{\text {ann }}$ : annealing-time; $A$ : area covered by recrystallized grains; $d_{\mathrm{exp}}$, std and $d_{\max }$ : expectation value, standard deviation and maximum grain size of the diameter of recrystallised olivine grains; $\varepsilon_{\text {tot }}$ : total strain determined from sample shortening after quenching.

$\mathrm{p}$ Experiment performed in a piston cylinder apparatus.

(1) Druiventak et al. (2011).

(2) Druiventak et al. (2012).

nd: not determined

3. To simulate creep during the period of stress relaxation three experiments were conducted with the first deformation stage as in 1) and continued deformation during heating and annealing at $1000^{\circ} \mathrm{C}$ and $2 \mathrm{GPa}$ for ca. $70 \mathrm{~h}$ (Table 2). In these "kick and creep" experiments, the piston was not retracted before heating and annealing. During one experiment (B9037) the axial piston remained at its final position of the first deformation step. During heating stress relaxation may have been partly counteracted by thermal expansion of the piston and the sample. Stress relaxation then dominated during isothermal annealing. The axial piston was advanced from its end position with a velocity of $0.15 \mathrm{~mm} \mathrm{~h}^{-1}$ during experiment B9039 for ca. $0.7 \mathrm{~h}$ during heating from 600 to $850^{\circ} \mathrm{C}$. In experiment B9038 the piston was advanced with a velocity of $0.75 \mathrm{~mm} \mathrm{~h}^{-1}$ during the entire heating period lasting for ca. $2 \mathrm{~h}$.

4. To simulate a repeated seismic event, "kick-cookkick" experiments were carried out comprising deformation and subsequent quasi-isostatic annealing as in
1) and finally a second deformation step at $1 \mathrm{GPa}$ and $300{ }^{\circ} \mathrm{C}(\mathrm{B} 9040)$ or $600^{\circ} \mathrm{C}(\mathrm{B} 9014)$, experiment B9015 was deformed during both high-stress stages at $600{ }^{\circ} \mathrm{C}$ and $2 \mathrm{GPa}$ (Table 2).

5. One reference experiment (B9044, Table 2) was carried out without the first deformation but starting with isostatic annealing at $1000^{\circ} \mathrm{C}$ for $70 \mathrm{~h}$ followed by deformation at $600^{\circ} \mathrm{C}$ and $1 \mathrm{GPa}$ confining pressure ("cook and kick").

The "kick and cook" and "kick and creep" experiments follow the original set up for studying quartz-microstructure development during coseismic loading and postseismic relaxation (Trepmann et al., 2007; Trepmann and Stöckhert, 2013), later applied to natural peridotites (Druiventak et al., 2012). Experiments with separate stages of deformation and successive annealing have also been performed on other geomaterials, e.g., single quartz crystals (e.g., Hobbs, 1968), synthetic rock salt (e.g., Piazolo, 2006) as well as on analogue materials (e.g., Urai and Humphreys, 2000). 
Table 2. Mechanical data of experiments of "kick and creep" (a) and "kick-cook-kick" (b) experiments.

\begin{tabular}{|c|c|c|c|c|c|c|c|c|c|c|c|c|c|c|c|c|c|c|c|}
\hline \multicolumn{20}{|l|}{ (a) } \\
\hline \multirow[b]{3}{*}{ sample\# } & \multicolumn{5}{|c|}{ High-stress deformation ("kick") } & \multirow{2}{*}{\multicolumn{11}{|c|}{$\begin{array}{l}\text { Low-stress deformation at high temperature ("creep") } \\
\qquad p_{\mathrm{c}}=2 \mathrm{GPa}\end{array}$}} & & & \\
\hline & & & $p_{\mathrm{c}}=1 \mathrm{GPa}$ & & & & & & & & & & & & & & & & \\
\hline & $\begin{array}{l}T_{\mathrm{c}, \mathrm{def}} \\
{\left[{ }^{\circ} \mathrm{C}\right]}\end{array}$ & $\begin{array}{l}T_{\mathrm{m}, \mathrm{def}} \\
{\left[{ }^{\circ} \mathrm{C}\right]}\end{array}$ & $\begin{array}{l}\mathrm{SR} \\
{\left[10^{-5} \mathrm{~s}^{-1}\right]}\end{array}$ & $\begin{array}{l}\Delta \sigma_{\max } \\
{[\mathrm{GPa}]}\end{array}$ & $\begin{array}{l}\varepsilon_{\max } \\
{[\%]}\end{array}$ & $\begin{array}{l}T_{\mathrm{c}, \mathrm{ann}} \\
{\left[{ }^{\circ} \mathrm{C}\right]}\end{array}$ & $\begin{array}{l}T_{\mathrm{m}, \mathrm{ann}} \\
{\left[{ }^{\circ} \mathrm{C}\right]}\end{array}$ & $\begin{array}{l}t_{\mathrm{ann}} \\
{[\mathrm{h}]}\end{array}$ & $\begin{array}{l}A \\
{[\%]}\end{array}$ & $\begin{array}{l}d_{\exp } \\
{[\mu \mathrm{m}]}\end{array}$ & $\begin{array}{l}\mathrm{std} \\
{[\mu \mathrm{m}]}\end{array}$ & $\begin{array}{l}d_{\max } \\
{[\mu \mathrm{m}]}\end{array}$ & $\begin{array}{l}\mathrm{SR} \\
{\left[\mathrm{s}^{-1}\right]}\end{array}$ & $\begin{array}{l}\Delta \sigma \\
{[\mathrm{GPa}]}\end{array}$ & $\begin{array}{l}\varepsilon_{\mathrm{tot}}-\varepsilon_{\max } \\
{[\%]}\end{array}$ & $\begin{array}{l}\varepsilon_{\text {tot }} \\
{[\%]}\end{array}$ & & & \\
\hline B9037 & 301 & 309 & 6.6 & 1.1 & 17 & 1001 & 1005 & 70.2 & 25.6 & 5.7 & 2.9 & 22.0 & $4 \times 10^{-7}$ & 0.30 & 10 & 27 & & & \\
\hline В9038 & 301 & 326 & 7.0 & 1.5 & 21 & 1001 & $\mathrm{Nd}$ & 70.8 & nd & 6.4 & 5.4 & 29.5 & $1 \times 10^{-6}$ & 0.44 & 19 & 50 & & & \\
\hline B9039 & 602 & 629 & 7.7 & 1.0 & 17 & 1001 & 955 & 69.8 & 23.6 & nd & nd & nd & $6 \times 10^{-7}$ & 0.39 & 16 & 33 & & & \\
\hline \multicolumn{20}{|l|}{ (b) } \\
\hline & \multirow{2}{*}{\multicolumn{5}{|c|}{$\begin{array}{l}\text { First deformation ("kick") } \\
\left.p_{\mathrm{c}}=1 \mathrm{GPa} \text { (except B9015: } 2.0 \mathrm{GPa}\right)\end{array}$}} & \multirow{2}{*}{\multicolumn{7}{|c|}{$\begin{array}{l}\text { Quasi-isostatic annealing ("cook") } \\
p_{\mathrm{c}}=2 \mathrm{GPa}\end{array}$}} & \multirow{2}{*}{\multicolumn{7}{|c|}{$\begin{array}{l}\text { Second deformation ("kick") } \\
\left.p_{\mathrm{c}}=1 \mathrm{GPa} \text { (except B9015: } 2 \mathrm{GPa}\right)\end{array}$}} \\
\hline & & & & & & & & & & & & & & & & & & & \\
\hline sample\# & $\begin{array}{l}T_{\mathrm{c}, \mathrm{def}} \\
{\left[{ }^{\circ} \mathrm{C}\right]}\end{array}$ & $\begin{array}{l}T_{\mathrm{m}, \mathrm{def}} \\
{\left[{ }^{\circ} \mathrm{C}\right]}\end{array}$ & $\begin{array}{l}\mathrm{SR} \\
{\left[10^{-5} \mathrm{~s}^{-1}\right]}\end{array}$ & $\begin{array}{l}\Delta \sigma_{\max } \\
{[\mathrm{GPa}]}\end{array}$ & $\begin{array}{l}\varepsilon_{\max 1} \\
{[\%]}\end{array}$ & $\begin{array}{l}T_{\mathrm{c}, \mathrm{ann}} \\
{\left[{ }^{\circ} \mathrm{C}\right]}\end{array}$ & $\begin{array}{l}T_{\mathrm{m}, \mathrm{ann}} \\
{\left[{ }^{\circ} \mathrm{C}\right]}\end{array}$ & $\begin{array}{l}t_{\text {ann }} \\
{[\mathrm{h}]}\end{array}$ & $\begin{array}{l}A \\
{[\%]}\end{array}$ & $\begin{array}{l}d_{\exp } \\
{[\mu \mathrm{m}]}\end{array}$ & $\begin{array}{l}\mathrm{std} \\
{[\mu \mathrm{m}]}\end{array}$ & $\begin{array}{l}d_{\max } \\
{[\mu \mathrm{m}]}\end{array}$ & $\begin{array}{l}T_{\mathrm{c}, \text { def }} \\
{\left[{ }^{\circ} \mathrm{C}\right]}\end{array}$ & $\begin{array}{l}T_{\mathrm{m}, \mathrm{def}} \\
{\left[{ }^{\circ} \mathrm{C}\right]}\end{array}$ & $\begin{array}{l}\mathrm{SR} \\
{\left[10^{-5} \mathrm{~s}^{-1}\right]}\end{array}$ & $\begin{array}{l}\Delta \sigma_{\max } \\
{[\mathrm{GPa}]}\end{array}$ & $\begin{array}{l}\varepsilon_{\max 2} 2 \\
{[\%]}\end{array}$ & $\begin{array}{l}\varepsilon_{\mathrm{tot}}-\varepsilon_{\max 1} \\
{[\%]}\end{array}$ & $\begin{array}{l}\varepsilon_{\text {tot }} \\
{[\%]}\end{array}$ \\
\hline B9040 & 301 & 302 & 7.3 & 1.26 & 23 & 1001 & 1028 & 69.1 & 30.2 & 4.5 & 3.8 & 22.0 & 301 & 311 & 2.42 & nd & 16 & 11 & 34 \\
\hline B9014 & 602 & nd & 7.6 & 1.17 & 25 & 1001 & nd & 16.5 & 15.9 & 3.6 & 1.9 & 28.4 & 602 & nd & 5.81 & 2.0 & 9 & 12 & 37 \\
\hline B9015 & 601 & 592 & 7.6 & 1.29 & 18 & 1001 & nd & 16.6 & 20.0 & 4.9 & 3.7 & 23.5 & 602 & nd & 4.94 & 2.0 & 9 & 18 & 36 \\
\hline B9043 & 602 & nd & 7.4 & 1.27 & 19 & 1001 & nd & 69.0 & nd & nd & nd & nd & 601 & nd & 5.28 & 2.1 & 11 & 20 & 39 \\
\hline B9044 & & & no deformatio & & & 1001 & 971 & 69.9 & nd & nd & nd & nd & 601 & 570 & 8.34 & 2.1 & 15 & 11 & 11 \\
\hline
\end{tabular}

Notation for table heads as for Table 1; numbers quoted in italic: strain rate and stress during creep estimated as described in the text.

\subsection{Analytical techniques}

The olivine microfabrics of tested samples were analysed by polarization microscopy, scanning electron microscopy (SEM) including electron back scatter diffraction (EBSD), and transmission electron microscopy (TEM). Polarization microscopy was performed on polished thin sections $(30 \mu \mathrm{m}$ thick). A SEM (LEO 1530) instrument equipped with field emission gun and forescatter detector was used for automated EBSD measurements with a step size of 0.7 to $1 \mu \mathrm{m}$. For TEM analysis, a Phillips EM301 microscope was operated at $100 \mathrm{kV}$. TEM foils ( 100 to $200 \mathrm{~nm}$ thick) were prepared by the focused ion beam (FIB) technique using a FEI Quanta200 3-D microscope.

The area covered by new grains, was mapped for all samples relying on images gained by optical microscopy (see Tables 1 and 2). EBSD measurements provided information on the spatial distribution of the crystallographic orientation of new grains. Since new grains were generally too small to be analysed by polarization microscopy in $30 \mu \mathrm{m}$ thick sections, EBSD maps were also used for grain size analysis, despite the general difficulty to distinguish between misindexing and small real grains. Grain sizes were estimated using a threshold of a relative crystallographic misorientation angle of $10^{\circ}$ to formally distinguish between subgrains and grains. The quoted grain sizes represent the diameter of a circle of equivalent area. Given the applied step size of 0.7 to $1 \mu \mathrm{m}$ for automatic EBSD measurements, grains with a diameter below $2 \mu \mathrm{m}$ were neglected. The average grain diameter is given as the expectation value of the associated grain size distribution. Variability in grain size within a sample is represented by the standard deviation in grain size (see Tables 1 and 2). Typically, grain size distributions show the maximum for the lowest grain size bin $(<5 \mu \mathrm{m})$, then grain size frequencies rapidly decrease to zero. Maximum size of new grains is reported as the diameter of the last bin class with a non-zero frequency. The skewness of grain size distributions is to some extent affected by the automatic detection of

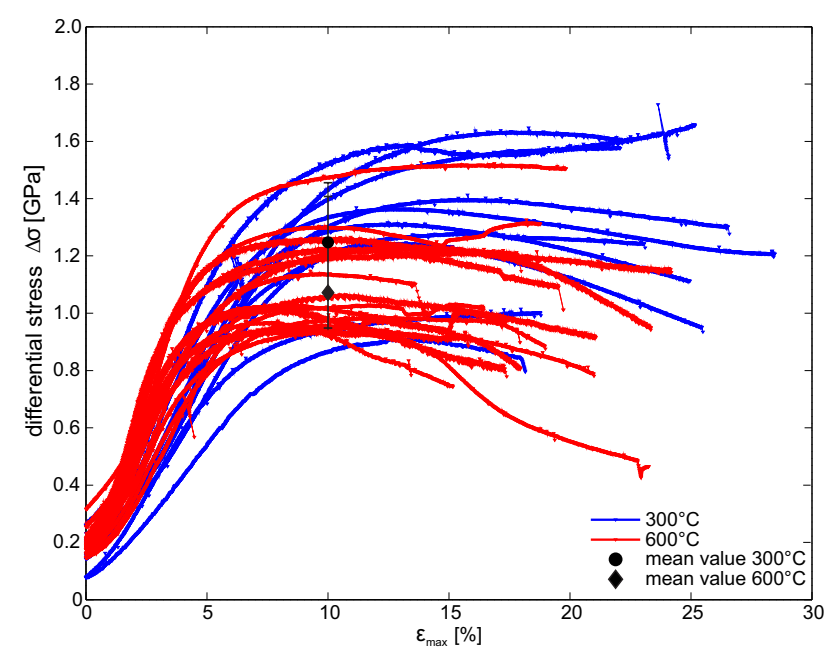

Fig. 1. Stress-strain curves for deformation at $300^{\circ} \mathrm{C}$ and $600{ }^{\circ} \mathrm{C}$. Mean value and standard deviation of stress at $10 \%$ strain indicate a weak temperature dependence of strength.

grains from EBSD data, likely overestimating the amount of small grains. Clearly, the absolute values for grain size determination are strongly dependent on the processing routine of the EBSD data. Here, all measurements were processed by strictly the same routine to ensure that the data are significant for a comparison of the results from the various experiments employing different deformation and annealing conditions.

\section{Results - mechanical data}

Maximum differential stress, $\Delta \sigma_{\max }$, and maximum strain, $\varepsilon_{\max }$, (sum of elastic and inelastic strain) reached during deformation were derived from stress-strain curves after friction correction (Rybacki et al., 1998). The maximum differential stress ranged between 1 and $1.5 \mathrm{GPa}$ during the initial deformation stage (Table 1). A weak temperature 

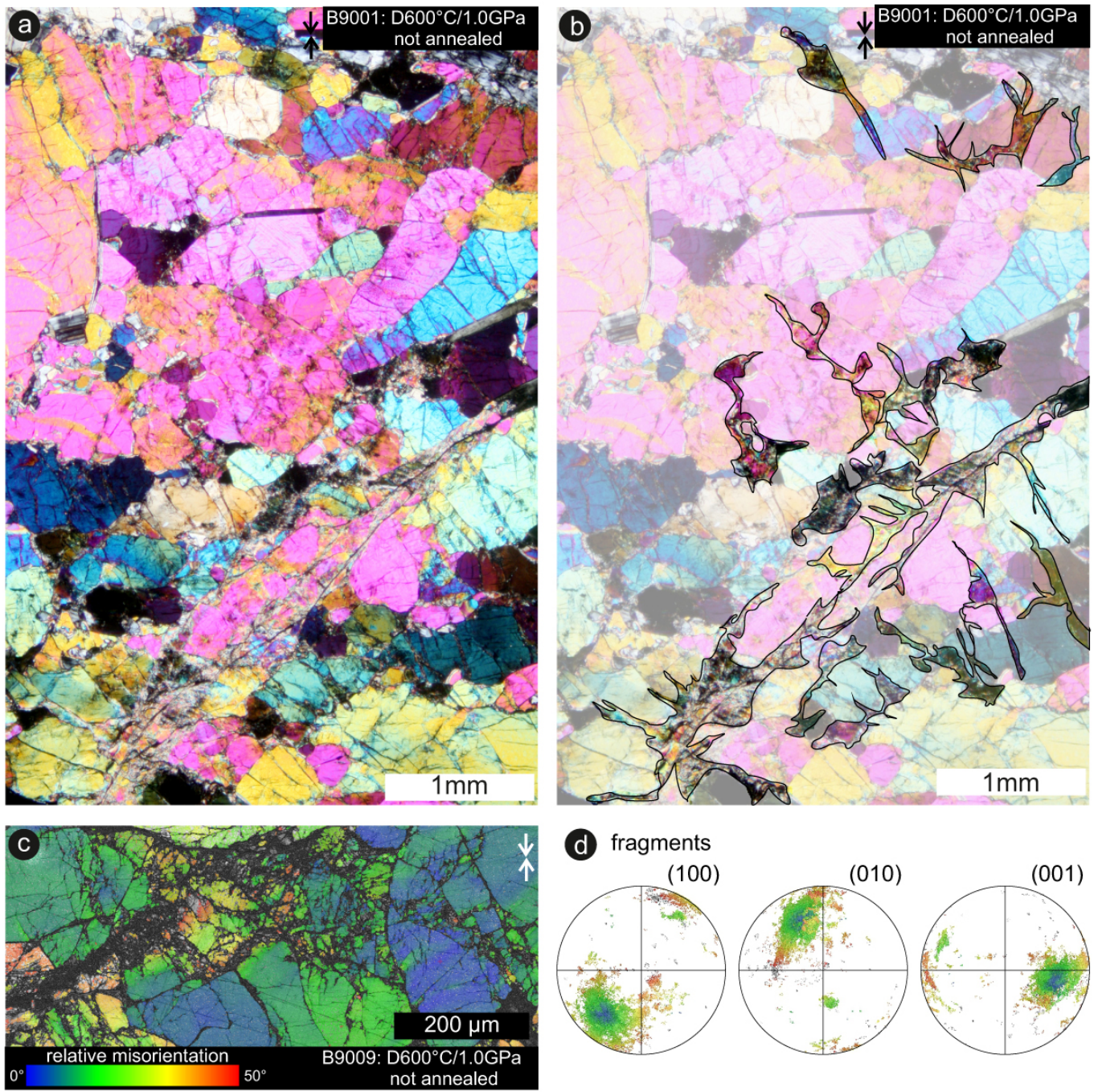

Fig. 2. (a), (b) Polarized light micrograph (crossed polarizers) of sample B901 after deformation at $600^{\circ} \mathrm{C}, 1 \mathrm{GPa}$ that did not experience subsequent annealing. The yellow lines in (b) encircle the highly damaged zones, identified by optical microscopy (in combination with EBSD and TEM analyses). The shortening direction is vertical, indicated by black arrows. (c) EBSD map (relative misorientation) of sample B909 after deformation at $600^{\circ} \mathrm{C}, 1 \mathrm{GPa}$ that did not experience subsequent annealing; the shortening direction is vertical, indicated by white arrows, and corresponding pole figures (d).

dependence of strength can be noticed from mean values of differential stress at $10 \%$ strain (Fig. 1). On average, samples deformed at $300^{\circ} \mathrm{C}$ show a higher strength than those deformed at $600^{\circ} \mathrm{C}$ (see also Druiventak et al., 2011).

The stress-strain curves yield maximum strains between 14 and $28 \%$, correlating well with the permanent shortening $\varepsilon_{\text {total }}$ between 5 and $33 \%$ as determined from calliper measurements on recovered samples after the experiments (Table 1). Shortening of samples in the reference annealing experiments without preceding deformation ("cook") amounts to $3 \%$ in the Griggs-type apparatus and $1 \%$ in the pistoncylinder apparatus (Table 1).

Most of the stress-strain curves show systematic softening with increasing strain (Fig. 1). Due to the inherent un- certainty of the friction corrections in solid-media apparatus (e.g., Rybacki et al., 1998; Holyoke and Kronenberg, 2010) it is possible that the curves indicating softening do not all reflect actual material behaviour. Yet, the cases for which stress decreases prominently with increasing strain (Fig. 1) correlate with the observation of local shear zones in the deformed samples (Fig. 2). The slight variations in applied strain rates do not affect strength (Table 1).

Strains $\varepsilon_{\text {creep }}$, accumulated during the "creep" stage in "kick and creep" experiments in which the piston was slowly advanced during heating or remained at its final position after the deformation stage during annealing, range from 10 to $29 \%$, as calculated from the difference between total strain determined from the shortening of the sample 
after the experiment and the strain derived from the stressstrain curves of the low-temperature deformation ("kick" stage) (Table 2). These strains correspond to approximate strain rates between $10^{-6}$ and $10^{-7} \mathrm{~s}^{-1}$ gained from simply dividing accumulated strain by the duration of the hightemperature stage (Table 2). Differential stress at this stage is estimated to be somewhat below $0.5 \mathrm{GPa}$ using the flow law for dislocation creep of olivine after Chopra and Paterson (1981) and assuming that olivine deforms by dislocation creep at the given temperature of $1000^{\circ} \mathrm{C}$ and the inferred strain rates. As the axial piston is not (B9037) or slowly advanced only during the heating stage (B9038, B9039), stresses and strain rates decrease with time during the creep experiment.

Strain during the second high-stress low-temperature deformation after isostatic annealing can be estimated in two ways: (1) taking the difference between the total strain $\varepsilon_{\text {tot }}$ representing the permanent shortening of the sample and the strain $\varepsilon_{\max 1}$ derived from the stress-strain curves of the first deformation leads to 11 to $20 \%$; (2) directly analyzing the "second" stress-strain curve gives comparable strains $\varepsilon_{\max } 2$ of 9 to $16 \%$ (Table 2). Maximum differential stresses during the second deformation stage in kick-cook-kick experiments exceed those observed during the first. The friction characteristics changed relative to the first deformation stage when the experiment was cooled down to the temperatures of the second deformation stage $\left(300,600^{\circ} \mathrm{C}\right)$ after extended hightemperature annealing rendering the quoted stresses of the second stage more uncertain. Despite this uncertainty, the recorded values of stress are systematically higher for the second deformation stage compared to the first, suggesting that a significant reduction in strength from the first to the second deformation stage is unlikely. Also, strength determined from the reference experiment without a first deformation stage is similar to the ones determined during the first deformation cycles ("cook-kick").

\section{Results - olivine microfabric analysis}

Microstructures resulting from the high-stress deformation ("kick") are described in detail by Druiventak et al. (2011). In this study, we focus on the evolution of the olivine microfabric during subsequent annealing at different temperatures, durations, and stresses. As the high-stress deformation determines the olivine microfabric evolution during subsequent annealing, the main characteristics still ought to be summarised here. After "kick", the olivine grains with an original diameter of 0.2 to $1 \mathrm{~mm}$ show intragranular fractures, some of which may be pre-existent (Fig. 2a to c). Localized, highly damaged zones of a few tens to $100 \mu \mathrm{m}$ in width are characterized by systems of intergranular fractures separating fragments of various sizes (Fig. 2c). These fragments show strong patchy undulatory extinction in the polarization microscope (Fig. 2a, b) corresponding with high internal mis- orientation angles evidenced by EBSD data (Fig. 2c, d) and associated with a high density of dislocations, cellular domains, and voids as found by TEM (see Druiventak et al., 2011, 2012). Thus, the fragments show both, a misorientation between each other due to rigid body rotation and at the same time internal misorientation due to crystal-plastic deformation (Fig. 2c, d). The highly damaged zones constitute an area percentage of 5 to $7 \%$ (Fig. 2a, b).

\subsection{Microfabrics after reference experiments}

In samples from the reference annealing experiments at $1000^{\circ} \mathrm{C}$ for $70 \mathrm{~h}$ without preceding experimental deformation ("cook", B9026, B9036, Fig. 1), small grains with a diameter of 4 to $5 \mu \mathrm{m}$ occur locally along boundaries of original olivine crystals and pre-existent cracks in them. These small new grains cover an area of about 1 to $3 \%$ of the reference samples. Microstructures from the "cook and kick" reference experiment (B9044, annealed at $1000^{\circ} \mathrm{C}$ for $70 \mathrm{~h}$, deformed at $600^{\circ} \mathrm{C}$, Fig. 1) show some isometric new grains along boundaries of large original grains comparable to the "cook" reference samples (B9026, B9032) and otherwise the deformation microstructures compare well to the "kick" experiments, i.e., they comprise fractured original grains and highly damaged zones.

\subsection{Microfabrics after deformation and annealing ("kick and cook")}

\subsubsection{Types of grains}

In experimentally deformed and then annealed samples we differentiate two types of new grains on the basis of the microstructures of samples deformed at 300 or $600^{\circ} \mathrm{C}$ and annealed at the lowest temperature of $700^{\circ} \mathrm{C}$ for $144 \mathrm{hr}$ (Fig. 4). In these samples, a marked modification is not resolved by polarization microscopy compared to the microstructures observed immediately after deformation. In TEM, the highly damaged zones are still characterized by a high density of dislocations that occur in tangles and cellular domains, irrespective of deformation temperature (Fig. 4b: $600^{\circ} \mathrm{C}$, Fig. $4 \mathrm{~d}: 300^{\circ} \mathrm{C}$ ). The combination of EBSD maps and TEM observations (Fig. 4), however, reveals that new grains occur locally even at this lowest annealing temperature. We subdivide two different types of new grains:

1. Almost defect-free tiny $(<1 \mu \mathrm{m})$ crystalline volumes occur within crystalline material of very high defect density (Fig. 4b, d). New grains that develop from these cellular domains in highly damaged zones are subsequently referred to as "recrystallized grains". Voids occur along the boundaries of these grains but also within the matrix of high defect density.

2. Grains of a few micrometers or a few tens of micrometers with smoothly curved grain boundaries and an inherited defect density are interpreted to originate from 

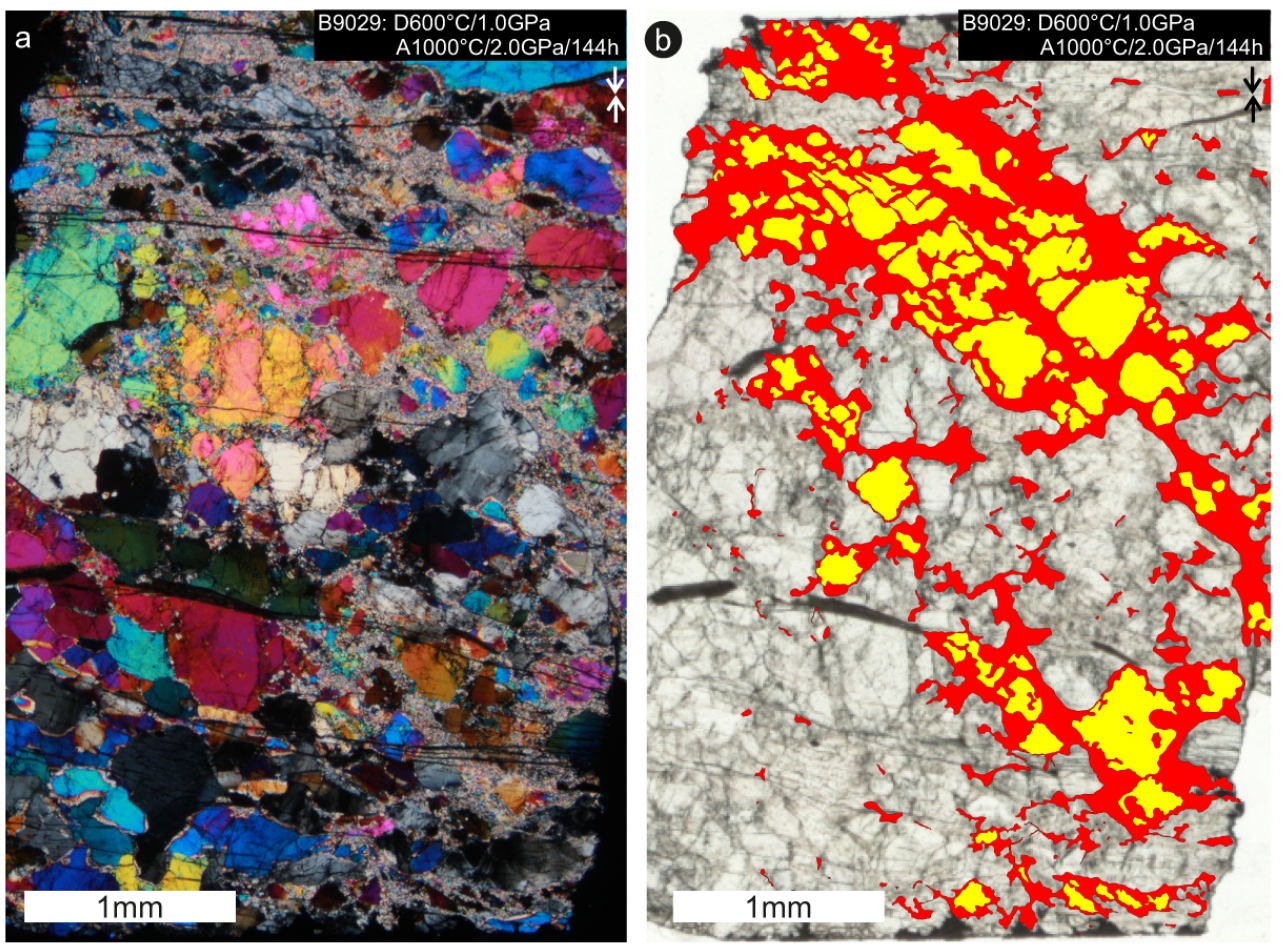

Fig. 3. (a) Polarized light micrograph (crossed polarizers) and (b) mapped area occupied by new grains for sample B9029 deformed at $600{ }^{\circ} \mathrm{C}$ and annealed at $1000^{\circ} \mathrm{C}$ for $144 \mathrm{~h}$. The red color in (b) represents the area occupied by new grains and yellow represents olivine porphyroclasts surrounded by new olivine grains. The shortening direction is vertical, indicated by arrows.

small fragments of original grains whose boundaries lost their angularity driven by curvature reduction during incipient heat treatment (Fig. 4c). These grains are referred to as "fragments". Voids of 1 to $2 \mu \mathrm{m}$ in diameter are present at three-grain junctions and smaller voids between two such grains.

The distinction between "fragment" and "recrystallized grain" thus reflects both, the variance in defect density and size. The characteristics of fragments and recrystallized grains change during annealing. To distinguish between fragments and recrystallized grains is straightforward when inspecting individual grains using TEM and highresolution EBSD maps but rather impossible on the scale of an entire sample. Therefore, they are summarized as "new grains" when describing bulk properties. A distinction between "fragment" and "porphyroclast" is established solely on the basis of size: Porphyroclasts are defined by a long axis of grains $>100 \mu \mathrm{m}$, i.e. $>10$ to $50 \%$ of the original grain size of the natural peridotites. Grains with inherited dislocation density (i.e., fragments plus porphyroclasts) are summarized as deformed grains.

\subsubsection{Development of the area occupied by new grains and their size during isostatic annealing}

A dependence of the size of new grains and the area they occupy on deformation temperature is not obvious from our data (Fig. 5a, b) but a strong dependence on annealing temperature and time (Figs. 5c, d, 6). The area occupied by new grains (up to $30 \%$ ) and the average grain diameter (3 to $10 \mu \mathrm{m}$ ) increase with annealing temperature and time (see also Table 1). New grains occur between porphyroclasts and in intragranular zones. Most prominently, they follow the original highly damaged zones generated during the highstress deformation stage (Fig. 3). The size of new grains varies strongly within one sample, as reflected by the high standard deviation (Table 1) and by grain size distributions derived from EBSD data (Fig. 7c, Fig. 8d). The variability slightly increases with increasing annealing temperature and time (Fig. 5c, d) not only in absolute values but also relative to the expectation values (Table 1).

Recrystallized grains and new grains originating from fragments differ prominently also after annealing at high temperature for a longer time: in samples after annealing for $144 \mathrm{~h}$ at $1000^{\circ} \mathrm{C}$, EBSD data reveal a heterogeneous distribution of small isometric recrystallized grains with smoothly curved high-angle grain boundaries and devoid of intracrystalline deformation features (Fig. 7). In contrast, fragments 

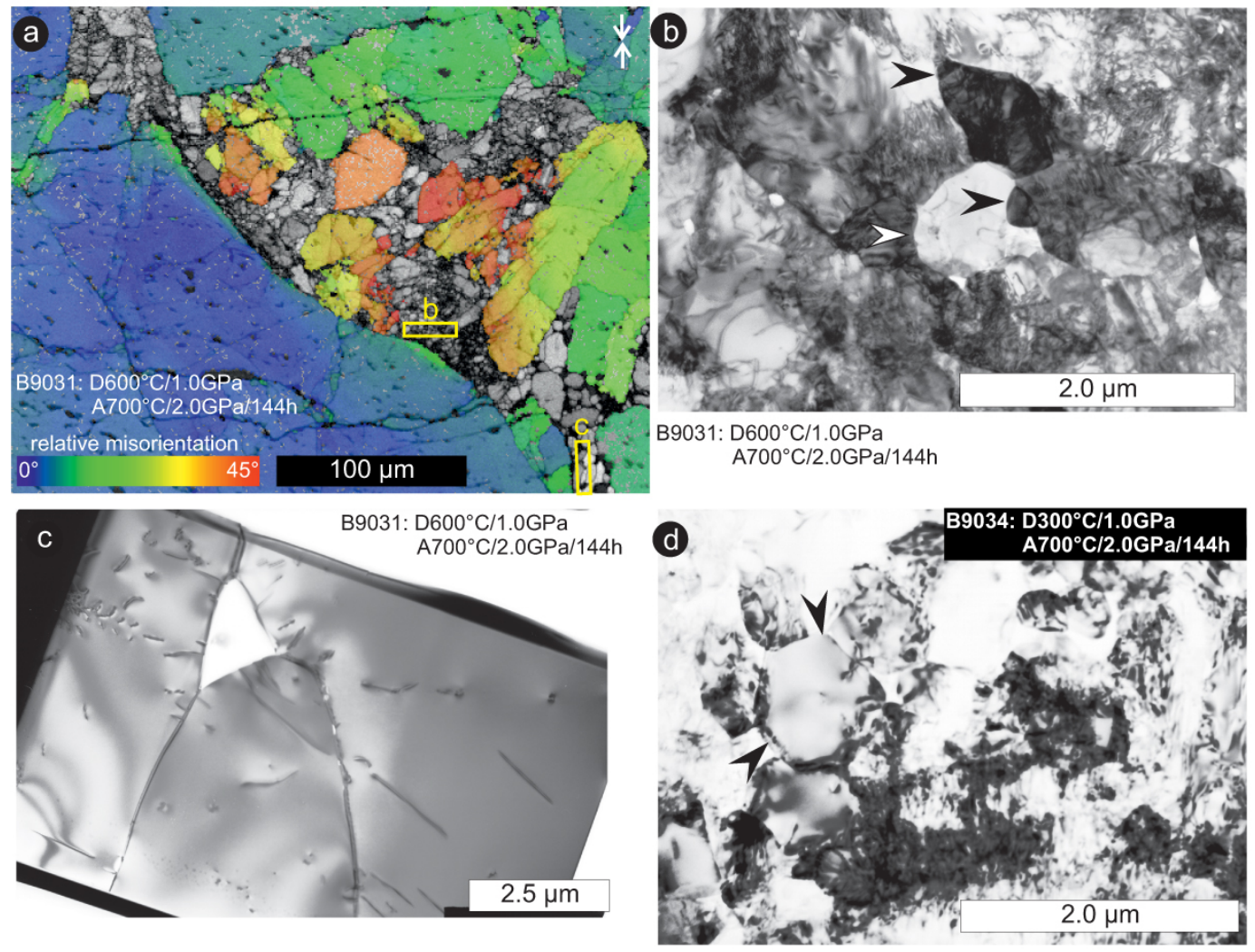

Fig. 4. (a) EBSD map with relative misorientation (sample B9031). The shortening direction is vertical, indicated by white arrows. FIB cuts for TEM samples are shown by yellow rectangles. (b, c) TEM micrographs of sample B9031, deformed at $600^{\circ} \mathrm{C}$ and annealed at $700^{\circ} \mathrm{C}$ for $144 \mathrm{~h}$. TEM sample locations are shown in (a). (d) TEM micrograph of a sample B9034 deformed at $300^{\circ} \mathrm{C}$ and annealed at $700^{\circ} \mathrm{C}$ for $144 \mathrm{~h}$. Note the "new grains", i.e. defect-poor crystallites (arrows in b, d) in a distorted matrix of high defect density still present after annealing in zones of high strain generated during deformation. In contrast (c) shows a "fragment", see text for explanation.

developed irregular grain shapes with sutured boundaries, undulatory extinction and sub-grain boundaries, i.e. internal crystallographic misorientation, as indicated by polarization microscopy and EBSD analysis (Fig. 7a, b).

After isostatic annealing at $1100^{\circ} \mathrm{C}$ for $70 \mathrm{~h}$, fragments (labelled "f" in Fig. 8a) show mostly concave and sutured boundaries and are thus distinguishable from isometrically shaped recrystallized grains with curved convex boundaries. Recrystallized grains typically retain a small diameter of $\leq 10 \mu \mathrm{m}$. Areas, where recrystallized grains occur concentrated and together with fragments of various size (Fig. 8a, d), are interpreted to represent former highly damaged zones. Grain size distributions overly decrease monotonically for deformed samples annealed at temperatures up $1000^{\circ} \mathrm{C}$ (Fig. 8d) but distributions of samples annealed at $1100^{\circ} \mathrm{C}$ show a decreased amount of grains in the lowest bin $(<5 \mu \mathrm{m}$, Fig. $8 \mathrm{a}, \mathrm{d})$. The increase in average and maximum grain diameter with higher annealing temperature and time is also reflected by the higher variance in grain sizes (Table 1).

Generally, less than a few percent of the area of a sample are covered by recrystallized grains after annealing at temperatures of $\leq 900^{\circ} \mathrm{C}$. Microstructural observations indicate that the highly damaged zones formed during deformation are completely replaced by defect-poor new grains after annealing for $70 \mathrm{~h}$ at $900^{\circ} \mathrm{C}$. At higher temperatures, the area occupied by new grains is larger than the optically defined highly damaged zones. Generally, the striking microstructure of porphyroclasts surrounded by new grains observed after annealing at temperatures of $\geq 900^{\circ} \mathrm{C}$ is similar to what is commonly addressed as core-and-mantle structure (e.g., Fitz Gerald and Stünitz, 1993; Passchier and Trouw, 2008; Stipp and Kunze, 2008).

In TEM, the different characteristics of fragments and recrystallized grains are apparent by their respective intracrystalline defects: fragments show low-angle grain boundaries arranged in short, commonly subparallel sets and a low to moderately high $\left(<10^{13} \mathrm{~m}^{-2}\right)$ dislocation density (Figs. $8 \mathrm{~b}$, c, 9). Recrystallized grains are free of low-angle grain boundaries and contain almost no dislocations (Figs. 8b, c, 9a, b, c, f). Boundaries between two recrystallized grains (Fig. 9a, b) as well as the boundaries between recrystallized grains and fragments (Figs. 9c, f, 10b, c) are smoothly curved and partly decorated by tiny voids. 

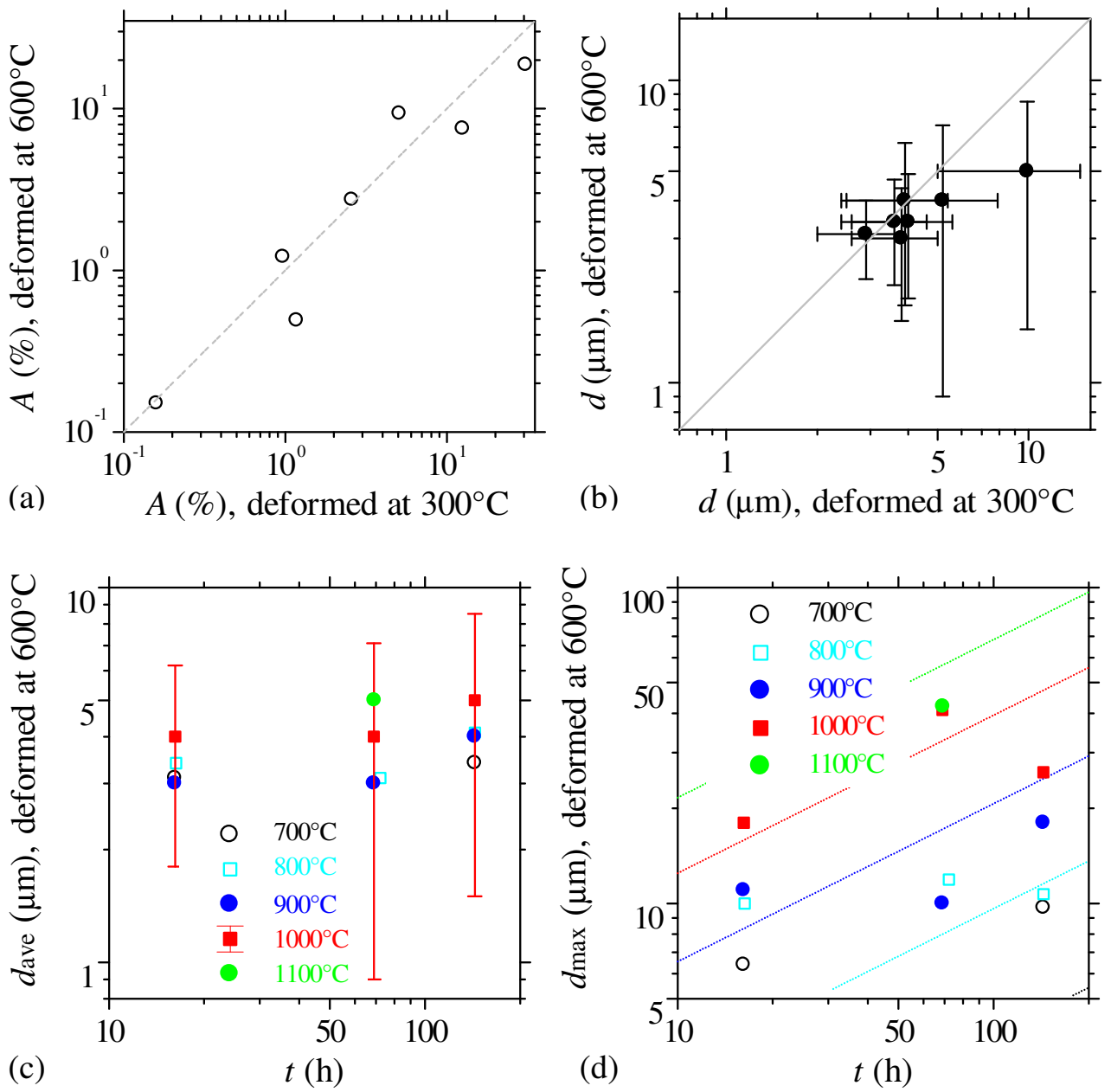

Fig. 5. Comparison of quantitative microstructure characteristics of annealing experiments following deformation at $300{ }^{\circ} \mathrm{C}$ and $600{ }^{\circ} \mathrm{C}$ : (a) Area occupied by new grains and (b) average grain diameter. The error bars reflect the standard deviation. (c) Average grain size and (d) maximum grain size as a function of annealing time for indicated annealing temperatures. In (c) we present the standard deviation by error bars only for the data at $1000^{\circ} \mathrm{C}$ for presentational clarity. Variability of results is comparable for all annealing temperatures (see Table 1). The dashed lines in (d) represent the empirical grain growth law after Karato (1980) with a starting grain size $d_{0}=0$.

The differentiation between fragments and porphyroclasts becomes increasingly ambiguous, as the grain size of porphyroclasts shrinks due to the growth of new grains (Fig. 8a). Despite this ambiguity in detail, however, it can be safely stated that an area $>70 \%$ of the sample is covered by porphyroclasts (host fragments $>100 \mu \mathrm{m}$ ) even at the highest annealing temperature of $1100^{\circ} \mathrm{C}$ (B9036, Fig. 8).

\subsubsection{CPO of new grains}

New grains in intragranular zones show a relative misorientation angle of more than $30^{\circ}$ compared to their host (Fig. 10a, b). There, misorientation patterns suggest a common axis possibly associated with rigid body rotation related to shearing within the highly damaged zone during the "kick" experiment. The crystallographic orientation of new grains derived from EBSD maps of larger areas of deformed and an- nealed samples shows similar maxima as the maps of the porphyroclasts (Fig. 11), in particular for low annealing temperatures $\left(700\right.$ and $\left.800{ }^{\circ} \mathrm{C}\right)$. The maxima in porphyroclasts orientation reflect a weak CPO of olivine present in the experimentally undeformed peridotite (Druiventak et al. 2011). With increasing annealing temperature the scatter in crystallographic orientation of new grains increases (Fig. 11). A systematic orientation relationship to the shortening direction is generally not obvious.

\subsection{Microfabrics after deformation and a subsequent low-stress, high-temperature stage ("kick and creep")}

The main characteristics of the microfabrics found after highstress deformation and high-temperature creep at $1000^{\circ} \mathrm{C}$ for $70 \mathrm{~h}$ and stresses about 3 times lower than those during the 


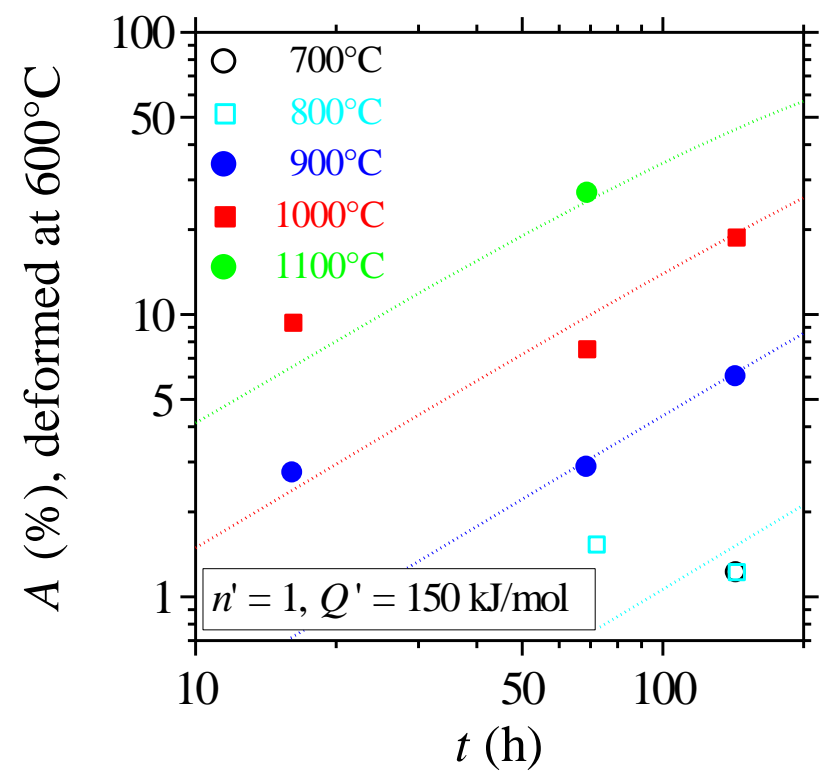

Fig. 6. Area occupied by new grains as a function of annealing time. The dashed lines indicate the predictions of the classical Avramikinetics Eq. (5) for the indicated effective exponent and effective activation energy. We restrict to representing results for samples deformed at $600^{\circ} \mathrm{C}$ for presentational clarity. Similar findings hold for samples deformed at $300^{\circ} \mathrm{C}$.

"kick" stage (i.e., 0.5 GPa) are comparable to those of samples that experienced isostatic annealing at the same temperature for the same duration. Core-and-mantle-like structures are found (Fig. 12a, b); the average diameter of new grains is about $6 \mu \mathrm{m}$ (see Tables 1 and 2); the observed CPO patterns are variable with strong scatter in orientations and no systematic correlation to the shortening direction, instead, orientation relations to the host (Fig. 11). Yet, an increase in the area occupied by new grains to $26 \%$ is observed for samples deformed in "kick and creep" experiments (Table 2a) compared to only 7 to $13 \%$ in the isostatically annealed samples at otherwise comparable conditions (Table 1).

\subsection{Microfabrics after deformation, annealing and renewed low-temperature deformation ("kick-cook-kick")}

In samples that experienced a second high-stress, lowtemperature deformation stage after an initial high-stress deformation and isostatic annealing ("kick-cook-kick"), elongate remnants of bent original grains with internal misorientation are observed in direct contact to zones of new grains (Fig. 12c, d). Strain accumulated during the second high-stress deformation therefore appears to localize in the porphyroclasts rather than in the fine-grained recrystallized zones.

\section{Discussion}

The recrystallization features observed in our reference samples annealed without preceding experimental deformation are interpreted to be a result of the rocks natural strain history rather than non-hydrostatic stress states during the experiments. The observed new grains supposedly develop by grain boundary migration of small crystalline, relatively defectfree volumes surrounded by naturally strained areas of the peridotites, i.e., along grain boundaries or pre-existent fractures. Yet, the area occupied by new grains observed after the isostatic reference "cook" experiments in the Griggs apparatus (B9026) and the piston cylinder apparatus (B9032) differs. The difference may be a result of sample to sample variability but may also indicate a poorer realization of isostatic conditions in the Griggs apparatus. If the latter is true, the microstructural observations of all experiments may be slightly biased by a fraction of new grains of up to $3 \%$ not necessarily directly correlated with the imposed experimental conditions. The sites most prone to recrystallization due to an inherited natural deformation history may, however, also accommodate the experimental deformation. If so, the area occupied by new grains observed during the reference experiments does not constitute a bias to our observations. The extent of these recrystallization phenomena is so restricted that their occurrence does not significantly affect our discussion. Furthermore, the "starting material" in nature will typically also have some strain energy stored from preceding events when a high-stress event takes place.

In the following, we firstly discuss the recrystallization processes for the two identified types of new grains distinguished from our "kick and cook" experiments, then specifically address the quantitative grain-size evolution during isostatic annealing, the kinetics of static recrystallization and finally the implications of our study regarding extrapolation to natural conditions and recognition of diagnostic microstructures in natural samples. We conclude with a brief note on reloading scenarios.

\subsection{Evolution of the two different types of new grains}

The "kick" stage at 300 and $600{ }^{\circ} \mathrm{C}$ leads to a transient marked grain size reduction by fracturing together with glide-controlled crystal-plastic deformation (i.e., lowtemperature plasticity) but evidence for dislocation creep with dynamic recrystallization is lacking (see also Druiventak et al., 2011, 2012). The variations in areas occupied by new grains and their size indicate that "nucleation and growth" processes are active to different degrees during heating and isostatic annealing with and without superposed creep. 

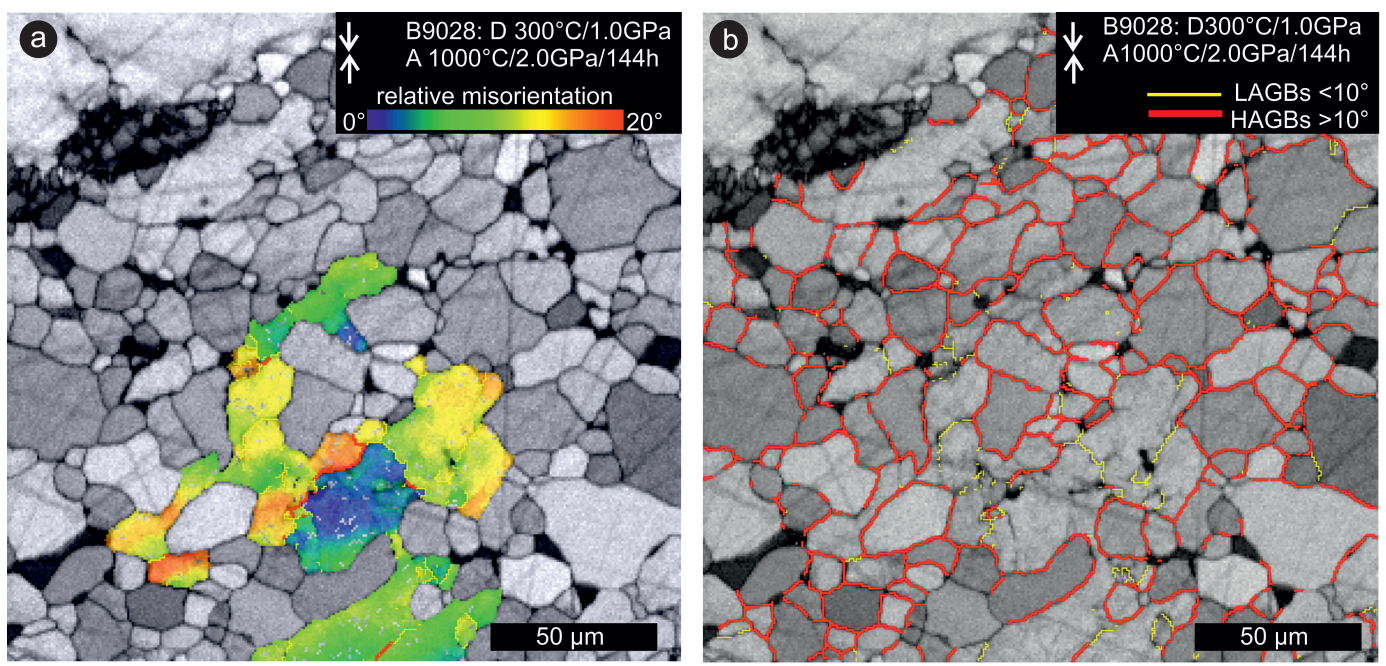

C Distribution function

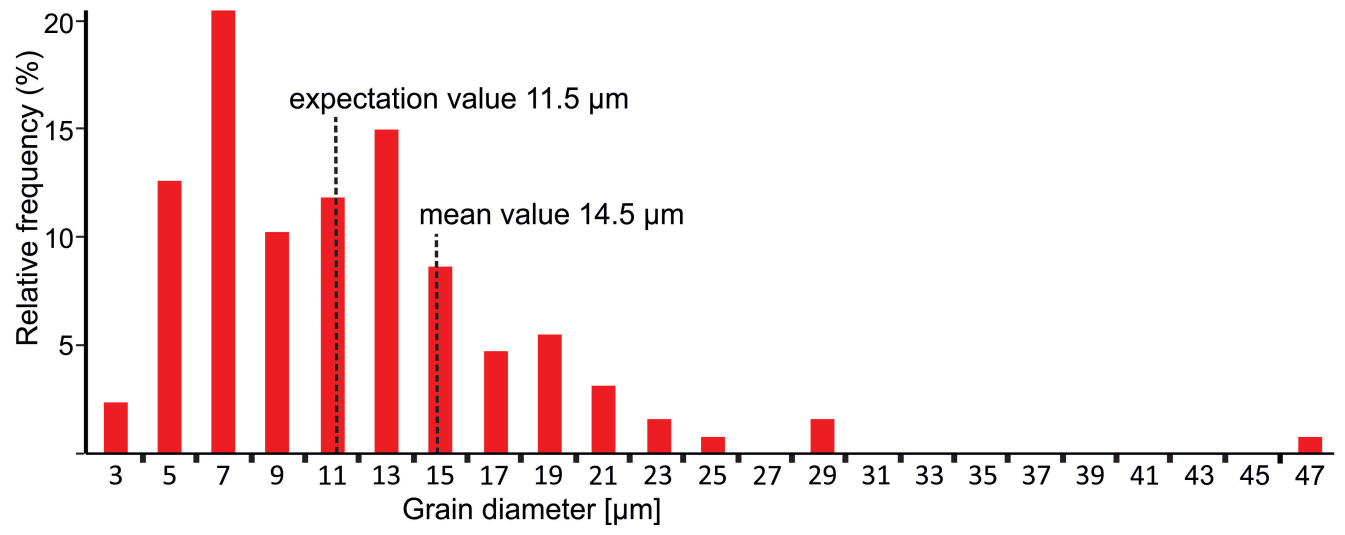

Fig. 7. EBSD map of sample B 9028 deformed at $300^{\circ} \mathrm{C}$ and annealed at $1000^{\circ} \mathrm{C}$ for $144 \mathrm{~h}$. (a) Highlighted is a grain with sutured boundaries indicating strain-induced grain boundary migration and with internal relative misorientation. The shortening direction is vertical, indicated by white arrows. (b) The same map, here with yellow lines indicating LAGBs and red lines indicating HAGBs. Note the contrast between the irregular shaped and the isometric new grains with smoothly curved HAGBs. (c) Grain size distribution (grains are selected manually) of area shown in a.

Based on the microstructural observations we distinguished two fundamentally different types of new grains:

1. The first type referred to as "recrystallized grains" evolved within highly damaged zones from cell structures, i.e., dislocation-free domains surrounded by dislocation tangles, formed by dislocation glide during high-stress deformation and possibly also some brittle mechanisms. At an early stage of annealing at $700^{\circ} \mathrm{C}$ (Fig. 4b, d), these grains are represented by defectfree crystallites with a diameter $<2 \mu \mathrm{m}$, surrounded by crystalline material containing a high density of tangled dislocation. Since annealing proceeds at isostatic conditions recrystallized grains do not develop internal deformation features. Their crystallographic orientation appears nearly random and only weakly controlled by the crystallographic orientation of the host crystal (Fig. 10a, b). Their orientation does not show a relation to the stress orientation of the initial deformation.

Cell structures are formed during deformation and thermally activated nucleation like in displacive phase transformations probably does not apply to static recrystallization. Nevertheless, some thermal effects such as cell-wall migration may contribute to the formation of the recrystallized grains. Thus, "nucleation" does not occur in the classical sense used for phase transformations but rather constitutes a process of "initiation", during which small crystalline volumes of low internal strain energy grow on the expense of deformed material (e.g., Humphreys and Hatherly, 2004). We still use the term "nucleation" here, given the small size of the precursors ("seeds" or "nuclei") embedded in the highly disordered crystal lattice. The formation of these recrystallized grains is different from 


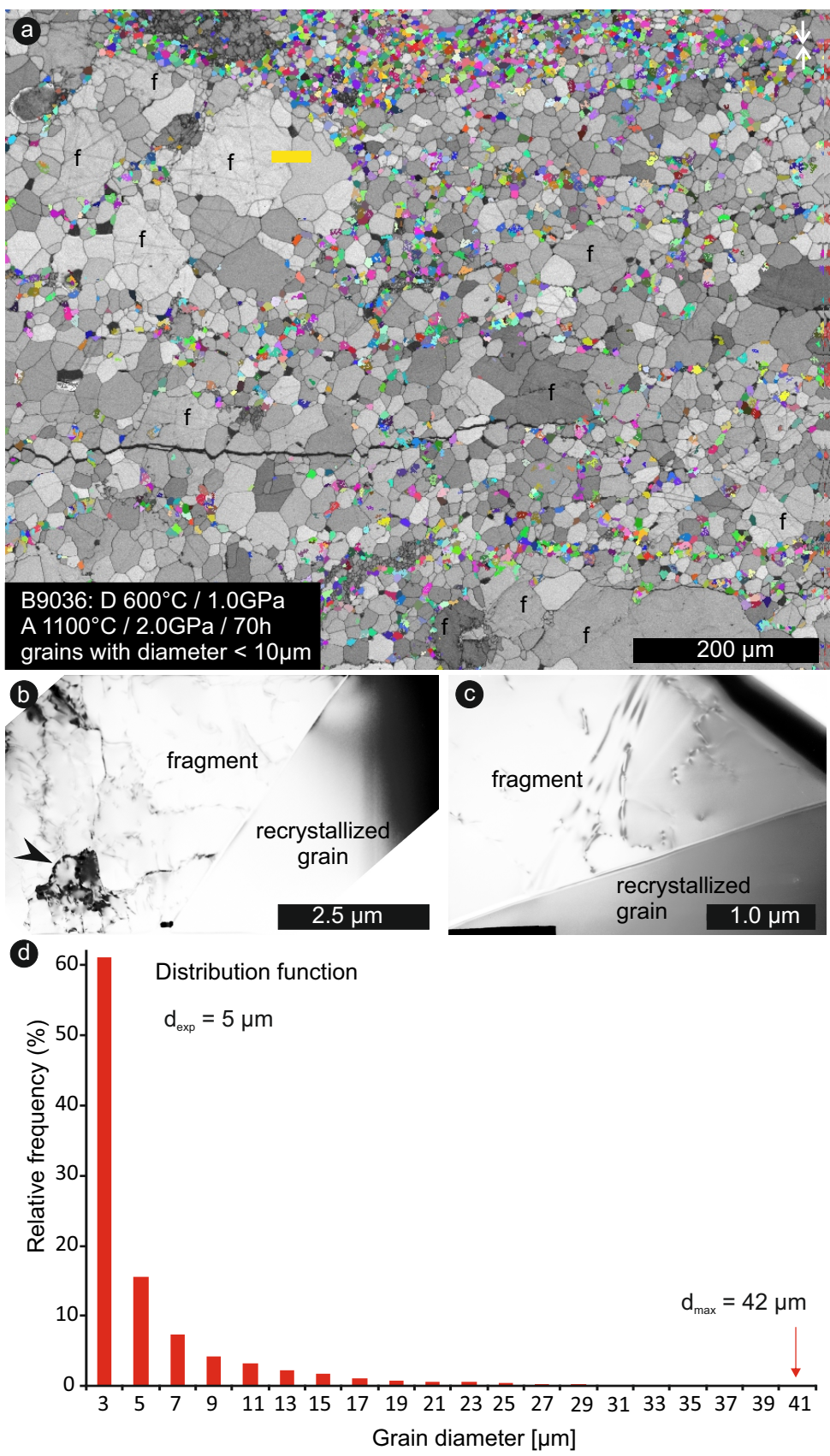

Fig. 8. (a) EBSD map shows grains with diameter $<10 \mu \mathrm{m}$ in randomly selected colours in sample B09036 after deformation at $600{ }^{\circ} \mathrm{C}$ and annealing at $1100^{\circ} \mathrm{C}$ for $\mathrm{ca} .70 \mathrm{~h}$. The shortening direction is vertical, indicated by white arrows. Original "fragments" (f) now show sutured and concave grain boundaries. Note contrast to isometric shape of new grains with mostly convex boundaries. Yellow bar marks location of FIB-prepared TEM sample of which micrographs are presented in $(\mathbf{b}, \mathbf{c})$. (b, $\mathbf{c})$ Fragments show LAGBs and a moderate free dislocation density. The grain boundary between host and new grain is straight. (d) Grain size distribution (grains are detected automatically) of area shown in (a).

subgrain rotation recrystallization (i.e., polygonization) or bulging recrystallization (e.g., Drury and Urai, 1990; Shimizu, 1998; Stipp and Kunze, 2008; Platt and Behr, 2011), for which the larger precursors inherit the crystallographic orientation of the host and which are processes that require ongoing deformation with continuous dislocation production, i.e., dynamic recrystallization. High misorientation between recrystallized grains developed from highly disordered lattice regions (Fig. 4b, d) and weak to absent orientation 

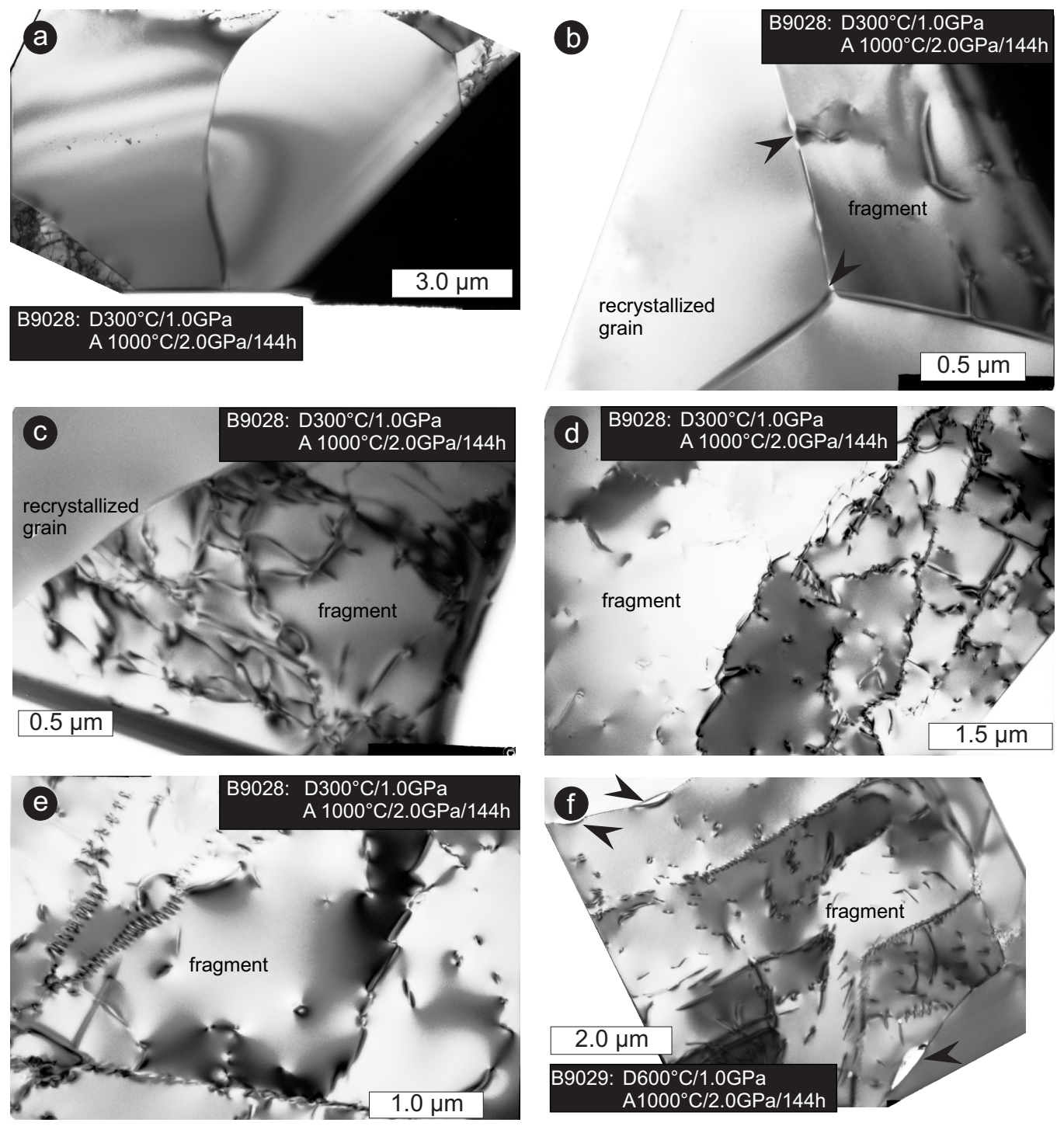

Fig. 9. TEM micrographs of sample B9028 deformed at $300^{\circ} \mathrm{C}$ and annealed at $100^{\circ} \mathrm{C}$ for $144 \mathrm{~h}$ (a to e) and of sample B9029 deformed at $600^{\circ} \mathrm{C}$ and annealed at $1000^{\circ} \mathrm{C}$ for $144 \mathrm{~h}$ (f). TEM micrographs show defect-free new grains with smoothly curved boundaries to host crystals containing LAGBs and dislocations. Note voids along grain boundaries (arrows). At three-grain junctions the angle between the boundaries encloses $120^{\circ}$ (b).

control by the host crystals have previously been observed in aggregates composed of quartz (Trepmann et al., 2007) and feldspar (Stünitz et al., 2003).

2. The second type of new grains, the fragments (Fig. 4c), differs from recrystallized grains and their precursors, the defect-free crystalline volumes $(<2 \mu \mathrm{m})$, mainly by (a) the inherited defects from the initial deformation stage, (b) their larger size (up to a few tens of $\mu \mathrm{m}$ ), and (c) the separation to other fragments by high-angle grain boundaries. After isostatic annealing, fragments contain low-angle grain boundaries and show sutured grain boundaries (Figs. 4c, 7, 8). Fragments that expe- rienced little rigid body rotation during comminution result in an orientation pattern with a systematic relation to the host crystal.

The differentiation in types of grains is necessary for the further discussion but in parts quite subtle, also because their characteristics change during the experiments. Some fragments (in particular small ones for which the average distance for a dislocation to the surface is small) may indeed anneal early on and then evolve exactly like recrystallized grains. In particular, the $\mathrm{CPO}$ and grain size analyses resting on large EBSD data sets comprise both, fragments and recrystallized 

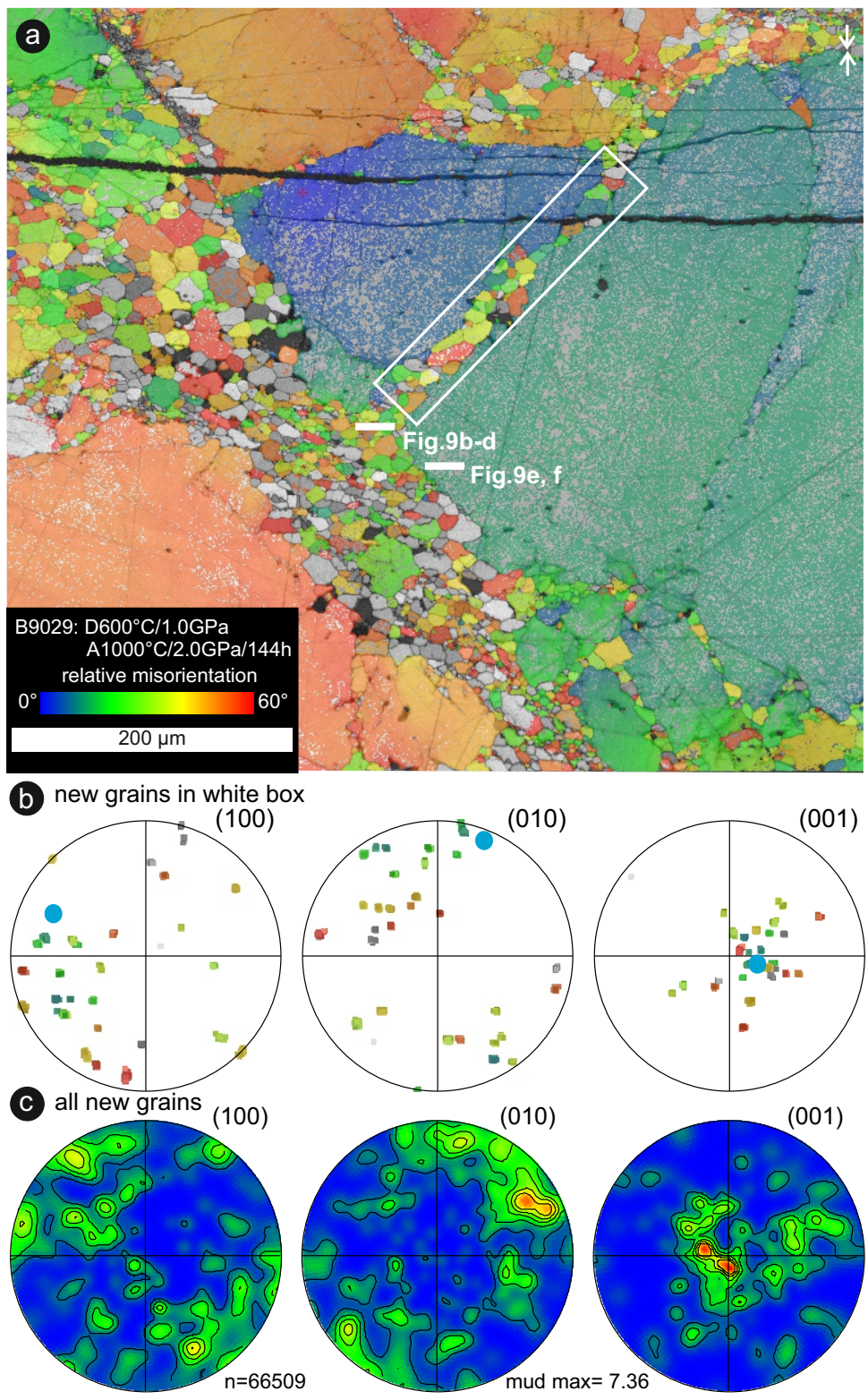

Fig. 10. (a) EBSD map showing new olivine grains in an intragranular zone and between two old grains after annealing at $1000{ }^{\circ} \mathrm{C}$ and $144 \mathrm{~h}$. The shortening direction is vertical, indicated by white arrows. The white bars indicate the location of FIB-prepared TEM samples (Fig. 9a to e). The white box indicates the area from which the crystallographic orientation is shown in the pole figures. (b) Pole figures displaying high misorientation angles between new grains (small dots, one point per grain) and host crystal (blue larger dot) in the intragranular zone (red rectangle). Note that the poles to (001) planes are less dispersed than those to (100) and (010), suggesting that the [001] direction is representing a rotation axis. (c) Density plot of pole figures of all new grains (complete data set) in the map.

grains. The weak CPO (Fig. 11) in areas composed of new grains is controlled by the original orientation of the host crystals and not interpretable in terms of intracrystalline glide systems requiring dynamic recrystallization resulting in recrystallized grains preferentially oriented with the active glide direction parallel to the stretching lineation and the glide plane in the foliation plane.

\subsection{Grain size evolution during isostatic annealing}

Given the short time of heating from $600{ }^{\circ} \mathrm{C}$ to the final annealing temperature (max. $2.3 \mathrm{~h}$ ) in comparison to the extended duration of annealing (16 to $144 \mathrm{~h}$ ), the contribution of growth during the heating phase can be neglected. Growth of defect-free recrystallized grains surrounded by crystalline material with a high defect density is initially driven by the 


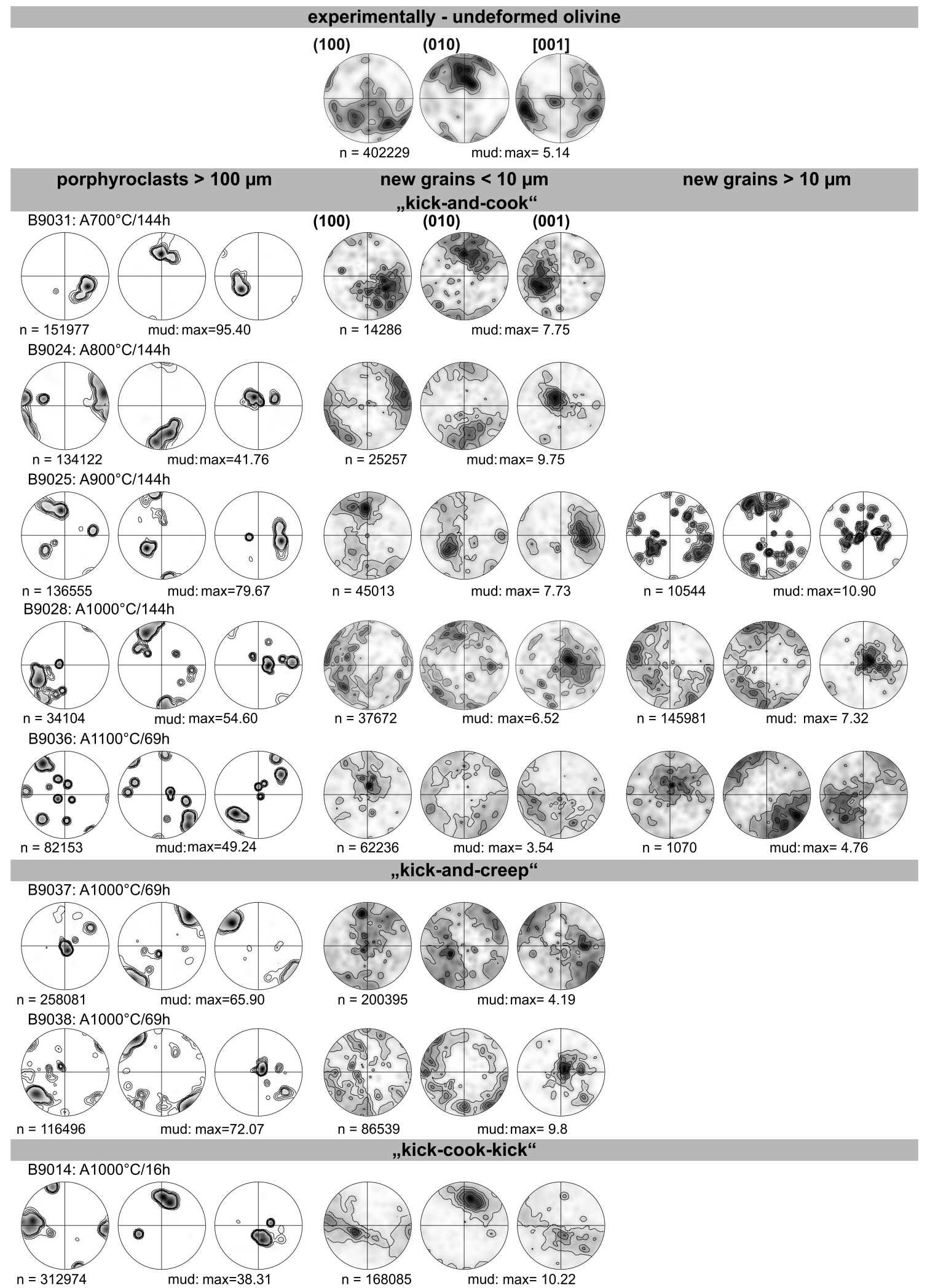

Fig. 11. Density plots of the crystallographic orientation of olivine crystals in an experimentally undeformed sample and in the deformed samples at the various experimental conditions (equal area projection, lower hemisphere, complete data set). The shortening direction is vertical in all images. 

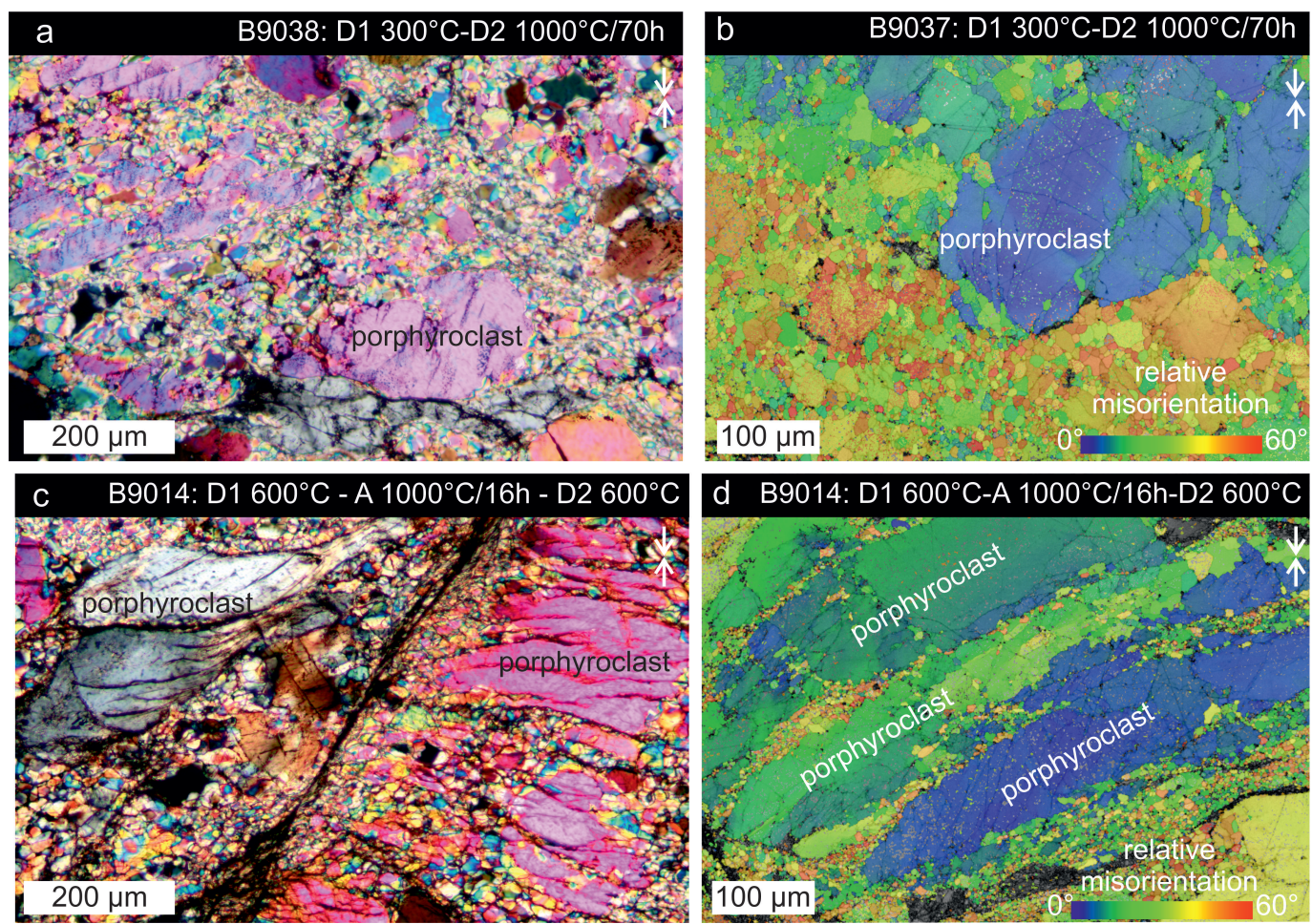

Fig. 12. (a) Polarized light micrograph (crossed polarizers) of sample $\mathrm{B} 9038$ and (b) EBSD map of sample $\mathrm{B} 9037$ both deformed at $300^{\circ} \mathrm{C}$ and then deformed at $1000^{\circ} \mathrm{C}$ at a low residual stress for ca. $70 \mathrm{~h}$ ("kick and creep" experiments). (c) Polarized light micrograph (crossed polarizers) and (d) EBSD map for sample B9014 after deformation at $600^{\circ} \mathrm{C}$ at high stress, annealing at $1000^{\circ} \mathrm{C}$ for $16 \mathrm{~h}$ and then again deformed at $600^{\circ} \mathrm{C}$ at high stress ("kick-cook-kick" experiments). The shortening direction is vertical in all images, indicated by white arrows.
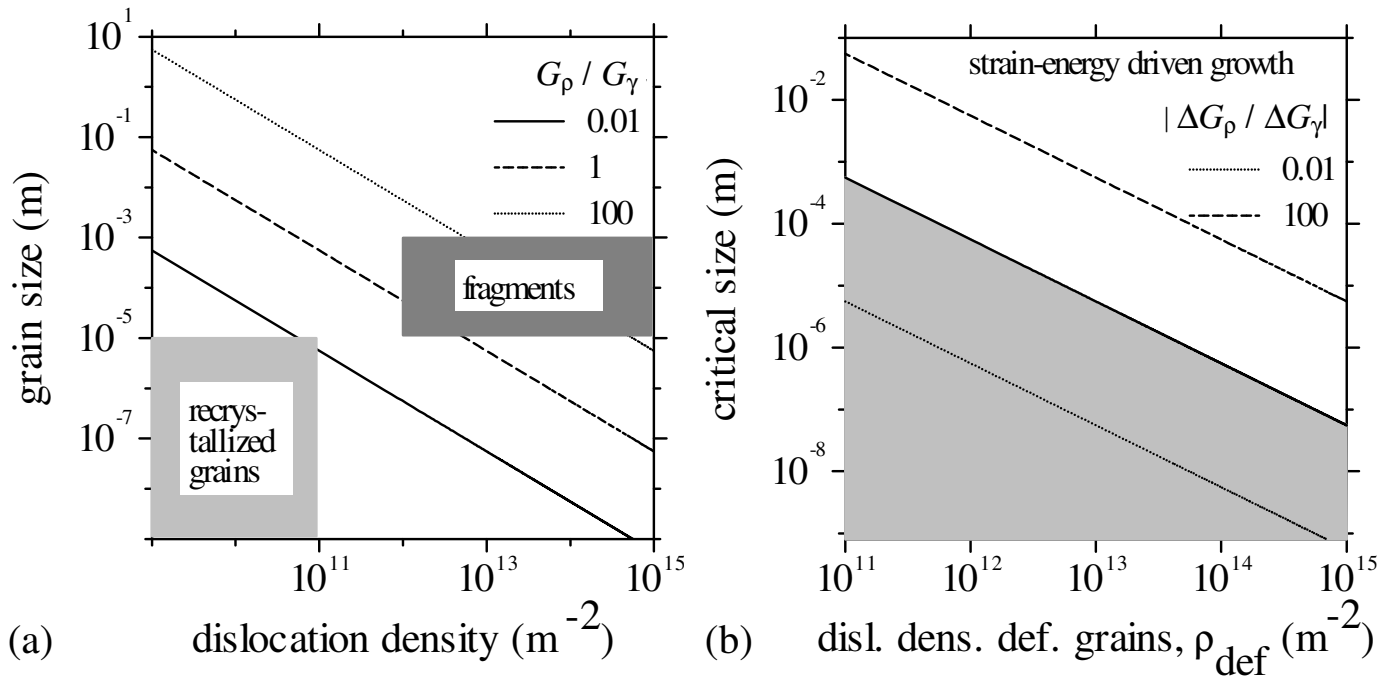

Fig. 13. (a) Relation between the free energies of recrystallized grains and deformed grains as determined by their size and their dislocation densities. (b) Critical size of grains for grain boundary migration in olivine (solid line, for example, a new grain needs a diameter of $1 \mu \mathrm{m}$ in an environment with a dislocation density of $>10^{14} \mathrm{~m}^{-2}$ for strain-energy driven growth to occur). The dashed lines represent the indicated relations between the two contributions to free energy. The line for $\left|\Delta G_{\rho} / \Delta G_{\gamma}\right|=0.01$ may also serve as an indication of the critical size relation for subgrains (index: sg) with $\gamma_{\mathrm{sg}} / \gamma=0.01$. Parameter estimates for olivine as given in Table 3 . The lines of constant ratio between strain energy as represented by dislocation density and interfacial energy relation were calculated assuming that crystallites have much smaller size and dislocation density than the deformed grains as supported by the ranges highlighted in (a). 
Table 3. (a) Parameter estimates for the quantitative analysis of the extended Avrami model. (b) Constraints on activation enthalpies of involved processes.

\begin{tabular}{|c|c|c|c|}
\hline \multirow[t]{5}{*}{ (a) } & parameter & estimate & reference \\
\hline & grain boundary energy $\gamma$ & $1 \mathrm{Jm}^{-2}$ & $\begin{array}{l}\text { Cooper and Kohlstedt (1982); } \\
\text { Duyster and Stöckhert (2001) }\end{array}$ \\
\hline & shear modulus $\mu$ & $50 \mathrm{GPa}$ & Jackson et al. (2002) \\
\hline & Burgers vector $b$ & $0.6 \mathrm{~nm}$ & $\begin{array}{l}\text { Deer et al. (1992); } \\
\text { Durinck et al. (2007) }\end{array}$ \\
\hline & $\begin{array}{l}\text { nucleus density } \eta=N / V \\
\text { initial dislocation density of } \\
\text { deformed material } \rho_{0}\end{array}$ & $\begin{array}{l}10^{18} \mathrm{~m}^{-3} \\
10^{15} \mathrm{~m}^{-2}\end{array}$ & \\
\hline \multirow[t]{9}{*}{ (b) } & process & activation enthalpy $\left(\mathrm{kJ} \mathrm{mol}^{-1}\right)$ & reference \\
\hline & grain growth & $\begin{array}{l}H_{\mathrm{gg}} \sim 160 \mathrm{~kJ} \mathrm{~mol}^{-1} \text { wet } \\
\left(H_{\mathrm{gg}} \sim 520 \mathrm{~kJ} \mathrm{~mol}^{-1} \mathrm{dry}\right)\end{array}$ & Karato (1989) \\
\hline & & $Q_{\text {creep }} \simeq H_{\mathrm{gbd}}^{\mathrm{Si}} \simeq H_{\mathrm{gg}}=335 \pm 75 \mathrm{~kJ} \mathrm{~mol}^{-1}$ & $\begin{array}{l}\text { Hirth \& Kohlstedt (2003); } \\
\text { Hackl \& Renner (2013) }\end{array}$ \\
\hline & grain boundary migration & $H_{\mathrm{gbm}} \simeq 210 \pm 20 \mathrm{~kJ} \mathrm{~mol}^{-1}$ & Toriumi (1982) \\
\hline & recovery kinetics & $H_{\rho}=300 \pm 15 \mathrm{~kJ} \mathrm{~mol}^{-1}$ & Kohlstedt et al. (1980) \\
\hline & & $H_{\rho}=460 \pm 42 \mathrm{~kJ} \mathrm{~mol}^{-1}$ & Toriumi \& Karato (1978) \\
\hline & & $H_{\rho}=240 \pm 43 \mathrm{~kJ} \mathrm{~mol}^{-1}$ sol gel & Farla et al. (2011) \\
\hline & & $H_{\rho}=355 \pm 81 \mathrm{~kJ} \mathrm{~mol}^{-1} \mathrm{SC} \mathrm{ol}$ & \\
\hline & lattice diffusion of $\mathrm{Si}$ & $H_{\mathrm{ld}}^{\mathrm{Si}}=529 \pm 41 \mathrm{~kJ} \mathrm{~mol}^{-1}$ & Dohmen et al. (2002) \\
\hline
\end{tabular}

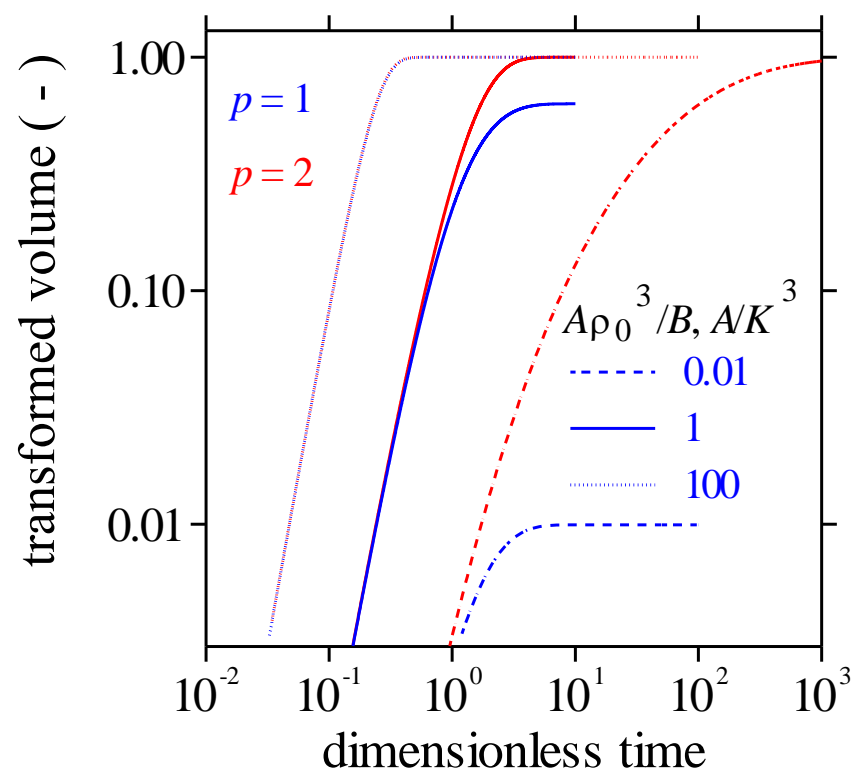

Fig. 14. Transformed volume according to Eq. (10) as a function of dimensionless time $\left(\hat{t}_{p=1}=B t\right.$ for $p=1$ and $\hat{t}_{p=2}=K \rho_{0} t$ for $p=2$ ) in the range of "measurable" volume fractions. The ratios of kinetics constants $A \rho_{0}^{3} / B$ and $A / K^{3}$ have to be on order of 1 or less for recovery kinetics to affect the transformation progress. reduction in strain and surface energies. Boundaries between defect-free recrystallized grains are solely controlled by interfacial free energy, whereas other grain boundaries (between deformed grains and recrystallized grains) are continuously migrating driven by gradients in the defect density.

A positive correlation between the final grain size attained during static recrystallization and annealing temperature as observed here (Fig. 5b, c, Table1) has also previously been reported, (e.g., Fig. 4.16 in Nicolas and Poirier, 1976) as has a negative correlation between resulting grain size and accumulated bulk strain during the preceding deformation (e.g., Nicolas and Poirier, 1976; Humphreys and Hatherly, 2004). Strain affects the number of nucleation sites (e.g., Humphreys and Hatherly, 2004) as much as it affects the degree and spacial extent of crystal damage. In addition, the defect content of the deformed material affects the driving force for growth and potentially also the grain boundary mobility. Spacial heterogeneity in local strain is characteristic for deformation in the regime of low-temperature plasticity associated with fracturing dominant in the "kick" steps of the experiments (Druiventak et al., 2011). Thus, even in a single sample the variability of local strain and associated inelastic deformation causes variations in the characteristics of new grains.

The observed range in grain sizes in samples from experiments after annealing at high temperatures $\left(\geq 900^{\circ} \mathrm{C}\right)$ and 

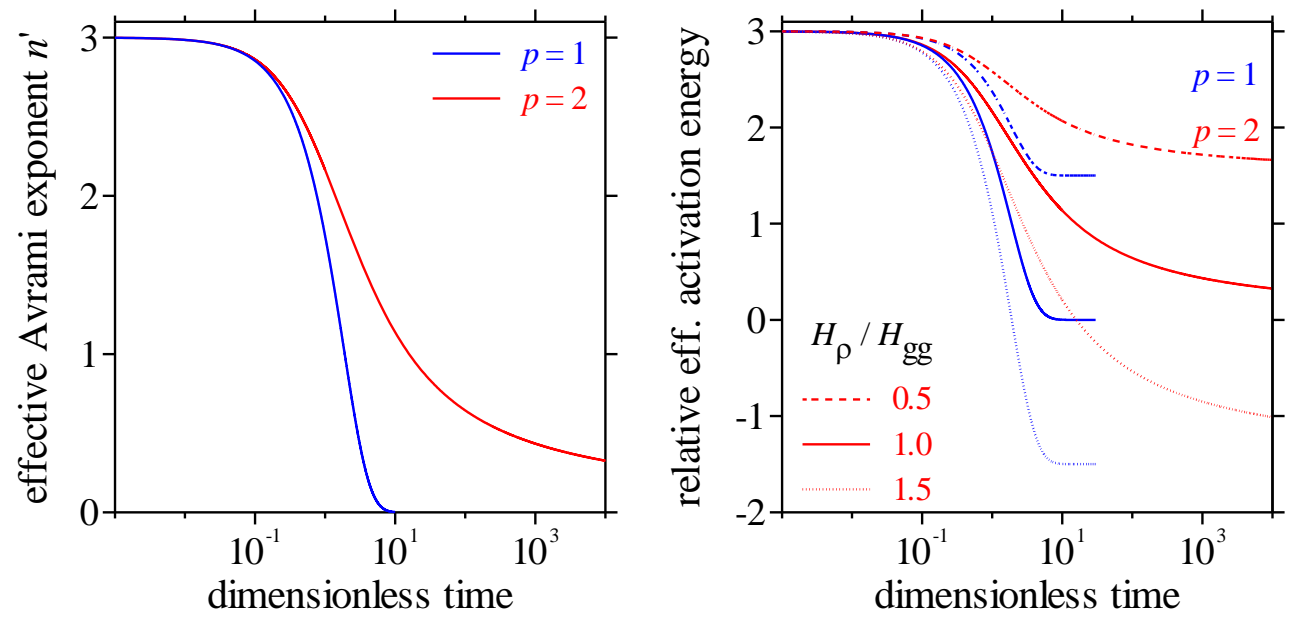

Fig. 15. (a) Effective Avrami exponent and (b) relative effective activation energy as a function of dimensionless time $\left(\hat{t}_{p=1}=B t\right.$ for $p=1$ and $\hat{t}_{p=2}=K \rho_{0} t$ for $p=2$, see Eq. 7). For (b) Eq. (10) was divided by $H_{\text {gg }}$ to arrive at relative values.
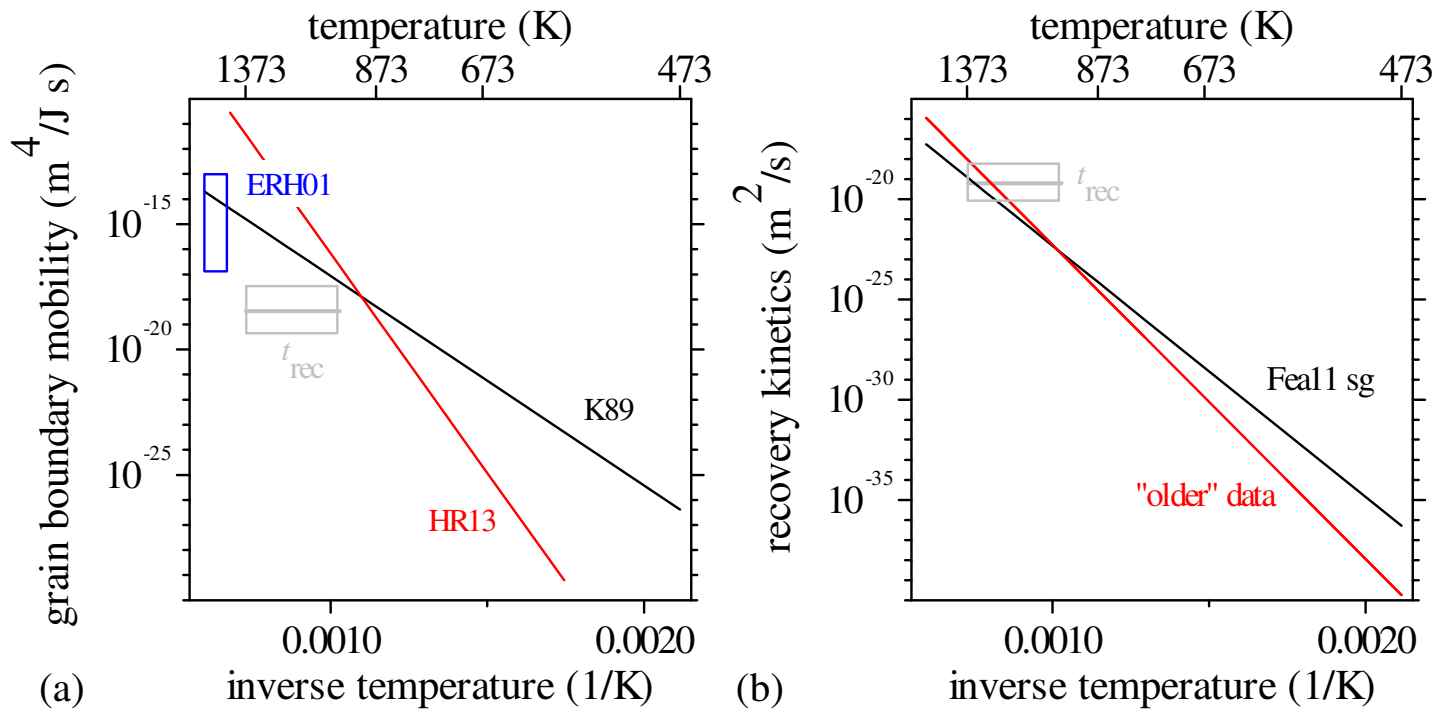

Fig. 16. Previously reported (a) grain boundary mobilities and (b) recovery kinetics parameters (for second-order kinetics) in comparison to values required for the extended Avrami model to be in accord with observed transformation kinetics (boxes labelled $t_{\text {rec }}$, see text for details). The box labelled ERH01 represents the literature review by Evans et al. (2001). "Older" data refers to the collection of data that consistently deviate from Farla's et al. (2011) [Fea11] results here given for samples prepared from sol gel.

long annealing times $(\geq 70 \mathrm{~h})$ can be explained by a negative correlation between grain size and strain and different evolutions of recrystallized grains and fragments during annealing (Fig. 8a, d, 10a, Table 1): The fine-grained $(<10 \mu \mathrm{m})$ zones represent sites of high nucleus density along former highly damaged zones (i.e., zones of high strain), where many nuclei are created and they mutually hinder each other in their growth due to impingement. In contrast, at some distance of the highly damaged zones fewer and larger new grains (up to $40 \mu \mathrm{m}$ ) occur (Fig. 10a), likely due to a lower nucleus density and/or predominant occurrence of fragments. Furthermore, variations in the driving force for growth during isostatic an- nealing have to be considered for the recrystallized grains that are almost free of defects and for the fragments that inherit the deformed microstructure (see for example Hackl and Renner, 2013, for an analytic expression of the dependence of a grain's size evolution on the relation between its energy state and that of its environment).

The driving force for growth of new grains, i.e., the difference in their free energy and that of their environment, $\Delta G$, is here simply associated with two defect concentrations, the density of interfaces (surface area per volume for a single grain, here represented by the inverse of grain size, i.e., a grain-shape dependent geometrical factor is neglected 
for simplicity but can be considered to be included in the uncertainty of the specific interface energy) and the density of dislocations (length of dislocations per volume),

$\Delta G=\Delta G_{\gamma}+\Delta G_{\rho}=\gamma\left(\frac{1}{d_{\mathrm{def}}}-\frac{1}{d_{\mathrm{rec}}}\right)+\mu b^{2}\left(\rho_{\mathrm{def}}-\rho_{\mathrm{rec}}\right)$,

where $\Delta G_{\gamma}$ and $\Delta G_{\rho}$ denote the difference in free energy associated with interfaces and dislocations, respectively; $d_{\mathrm{def}}$ and $d_{\text {rec }}$ represent the grain diameter of deformed grains (i.e., fragments and clasts) and recrystallized grains, respectively; $\rho_{\text {def }}$ and $\rho_{\text {rec }}$ are dislocation densities of deformed and recrystallized grains, respectively; $\gamma$ is the specific grain boundary energy, $\mu$ the shear modulus, and $b$ the Burgers vector.

In our samples, the free energy of recrystallized grains is dominated by their interfacial energy while that of deformed grains is dominated by strain energy represented by dislocation density (Fig. 13a). We therefore approximate the driving force by $\Delta G \simeq-\gamma / d_{\text {rec }}+\mu b^{2} \rho_{\text {def }}$ yielding a condition for the minimum size of a recrystallized grain to grow in expense of the deformed grains, $d_{\text {rec, } \min }=\gamma / \mu b^{2} \rho_{\text {def }}$. The critical size for a recrystallization nucleus in olivine aggregates calculates to 10 to $100 \mathrm{~nm}$ in volumes with a dislocation density of $\sim 10^{15 \pm 0.5} \mathrm{~m}^{-2}$ assuming $\gamma \sim 1 \mathrm{~J} \mathrm{~m}^{-2}$ (see Table $3 \mathrm{a}$ ). The minimum size directly scales with interfacial energy, thus the minimum size for subgrain nuclei may be even smaller than the value above due to the order of magnitude reduction in their interfacial energy relative to the used interface-energy value representative for large-angle boundaries. Once a material volume is solely composed of defect-free recrystallized grains, normal grain growth sets in controlled by a driving force that is dominated by the relative relation between the curvature of grain boundaries (e.g., Atkinson, 1988; Evans et al., 2001). At all stages, grain boundary migration may be affected by pinning due to voids present on the grain boundaries (Fig. 9) that are relics of low-temperature plasticity associated with brittle deformation preceding the annealing. Strain-induced migration of boundaries between defect-free recrystallized grains and fragments or porphyroclasts with inherited defect density can further proceed due to gradients in stored strain energy. The observation that the area occupied by new grains exceeds the area of original highly damaged zones after annealing at high temperature $\left(\geq 900^{\circ} \mathrm{C}\right)$ and long time ( $\geq 70 \mathrm{~h}$ ) may indeed be explained by ongoing strain-induced grain boundary migration after the complete replacement of the highly damaged zones.

Our data set is clearly affected by the lower limit in resolution of the EBSD-based grain size analysis. Yet, the size of new grains is sufficiently large for growth to be resolved for annealing temperatures exceeding $\geq 900^{\circ} \mathrm{C}$. Grain growth is traditionally modelled by laws of the form

$d_{(t)}^{m}-d_{0}^{m}=k_{\mathrm{gg}} t$,

where $k_{\mathrm{gg}}=k_{\mathrm{gg}, 0} \exp \left(-H_{\mathrm{gg}} / R T\right)$ (see e.g., Drolet and Galibois, 1971; Simpson and Aust, 1972; Evans et al., 2001) and
$\mathrm{H}_{\mathrm{gg}}$ is the activation enthalpy of grain boundary mobility. At face value, the observed size evolution of new grains is in fair agreement with predictions based on Eq. (2) using Karato's (1989) experimentally derived parameters $m=2$, $k_{\mathrm{gg}}, 0=1.6 \times 10^{-8} \mathrm{~m}^{2 / \mathrm{s}}$, and $H_{\mathrm{gg}}=160 \mathrm{~kJ} \mathrm{~mol}^{-1}$ (Fig. $5 \mathrm{c}$ ).

When data are available for 16 and $70 \mathrm{hr}$ long annealing stages at a given temperature, the difference in grain size is small (Fig. 5c). In conventional grain growth experiments such a plateau would indicate an effect of the starting grain size. The calculation of critical nucleus size however indicated much smaller values than these plateau values, suggesting that starting grain size can be neglected in Eq. (2) for recrystallized grains. This reasoning does not apply to fragments, though. Two alternative explanations deserve consideration. Firstly, the apparent plateau in grain size can simply be an effect of the convolution between the resolution limit of the EBSD analysis and the true grain-size distribution (indeed the majority of distributions decreases monotonically as expected for this type of resolution issue). The peaks of the distributions come close to or exceed the limit of resolution only for extended annealing at high temperature. For short durations and/or low temperature only the tail of the distributions is sampled. Secondly, continuous nucleation would also lead to an initial absence of growth since the distribution functions would be continuously reloaded at their small-size end. Yet, we consider a significant continuous nucleation rate during annealing unlikely, because the "nuclei" in this type of recrystallization phenomena are actually formed during the deformation stage.

\subsection{Kinetics of static recrystallization}

Formation of new grains from the deformed microstructure resembles a phase transformation, i.e. here the replacement of deformed material by material with lower dislocation density, involving overlapping and concurrent processes of nucleation, growth and impingement. We address the evolution of the structure as "transformation", where fragments either evolve similar to recrystallized grains or behave like components of the defect-loaded matrix otherwise constituted by clasts. Transformation kinetics is frequently modelled relying on the so-called Johnson-Mehl-Avrami-Kolmogorov (JMAK) equation (e.g., Johnson and Mehl, 1939; Christian, 2002, Liu et al., 2004). Below we first apply previously presented versions of the JMAK equation to our data before deriving an extended version that accounts for the time dependence of the driving force for growth. The complexities of the spacial distribution of new grains in heterogeneously deformed materials as the peridotite samples of this study cannot be accounted for in this modelling.

\subsubsection{Conventional Avrami-analysis}

For site saturation or continuous nucleation and isothermal conditions, the formation of recrystallized grains can be 
modelled by the conventional JMAK-kinetics equation

$X_{V}(t)=X_{A}(t)=1-\exp \left[-\left(k_{\text {trans }} t\right)^{n}\right]$,

where $X_{V}(t)$ and $X_{A}(t)$ denote transformed volume and area fractions, respectively, $t$ time, and $n$ is typically called the Avrami-exponent. The exponent depends on the dimensionality of growth and the rate-controlling process (e.g., interface vs. volume diffusion). Parameter $k_{\text {trans }}$ is a rate constant assumed to have an Arrhenius-type temperature dependence, i.e., $k_{\text {trans }}=k_{\text {trans, } 0} \exp \left(-Q_{\text {trans }} / R T\right)$, with an effective activation energy $Q_{\text {trans }}$ that is not an activation enthalpy of a single atomistic process but reflects nucleation and growth processes. At face value, our data suggest an Avrami-exponent close to 1 at least for extended annealing (Fig. 6) and an effective activation energy of $\sim 150 \mathrm{~kJ} \mathrm{~mol}^{-1}$ rather independent of the temperature at which the deformation took place preceding the annealing stage.

In the conventional approach an Avrami-exponent of 1 is representative of one-dimensional growth, an interpretation at odds with the microstructural observation that growth of grains occurs rather randomly in three dimensions. Spacial distribution of severely damaged material may reduce the dimensionality of growth to some extent but the very width and volume of the highly damaged zones clearly exceeds that of quasi-one-dimensional features. Such growth geometry is associated with $n=3$ and 4 for site saturation and continuous nucleation, respectively. Exponents also depend on the process that controls the transfer of atoms from deformed grains to new grains (interface kinetics vs. diffusion kinetics) but we suppose that the growth of new grains is diffusion controlled. Recent modifications of the JMAK-equation considered complex nucleation scenarios (Kempen et al., 2002; Liu et al., 2004) and yield time dependent exponents and activation energies. We however consider nucleation kinetics an unlikely cause for the low exponents observed here (see discussion on nucleation above) and follow a different path of extending the JMAK-approach by accounting for the time dependence of the driving force for growth.

\subsubsection{Extension of Avrami-analysis for time dependent growth rate}

We consider the situation that all nuclei are already formed before the heat treatment started but account for the time dependence of the growth rate of nuclei, $\dot{G}$, or their boundary velocity, $v(t)=\dot{G}$. Then, the transformed volume fraction evolves according to

$X_{V}(t)=1-\exp \left[-f N\left(\int_{0}^{t} v(\tau) \mathrm{d} \tau\right)^{3}\right]$,

where $f$ denotes a shape factor and $N$ the number of nuclei present (see also Luo, 2012). The exponent of 3 represents three-dimensional growth. For simplicity we consider isotropic growth of spherical particles, i.e., $f=4 \pi / 3$.
The positive argument of the exponential function in (4) represents the extended volume ratio, i.e., $X_{V}(t)=1-$ $\exp \left(-X^{\text {ext }}\right)$ with $X^{\text {ext }}=V^{\text {ext }} / V$.

In the context of static recrystallization of deformed materials, the driving force for grain boundary migration is the difference in dislocation density of the growing nuclei and their environment, the deformed material. We may assume that the dislocation density of the growing nuclei remains negligible during progressing annealing since static annealing excludes further deformation. Thus, the current dislocation density $\rho(t)$ (note, for the sake of presentational simplicity we drop the index "rec" for the size of recrystallized grains and the index "def" for the dislocation density of deformed material used in Eq. (1) in the following) of the relics of deformed material determines the driving force (reduction in free energy due to consumption of dislocations by moving grain boundaries, i.e., $F=\Delta G$ )

$F(t) \simeq-\frac{\gamma}{d(t)}+\mu b^{2} \rho(t)$.

New grains have to evolve above the minimum relation for a positive driving force of their growth, i.e., $F(t)>-\gamma / d_{\min }+$ $\mu b^{2} \rho(t)$ allowing us to introduce $F(t)=\chi \mu b^{2} \rho(t)$ with $\chi>0$. Here, we further rely on the standard linear relation between velocity and driving force (e.g., Ballufi et al., 2005)

$v(t)=m_{\mathrm{gb}} F(t) \simeq \chi m_{\mathrm{gb}} \mu b^{2} \rho(t)$

in which the mobility $m_{\mathrm{gb}}=\Omega D / \delta R T$ (with molar volume $\Omega$, grain boundary diffusion coefficient $D=$ $D_{0} \exp \left(-H_{\mathrm{gg}} / R T\right)$, and grain boundary width $\delta$ ) assuming that the kinetics of boundary migration can be described by an intrinsic boundary mobility independent of the actual driving force. Vandermeer et al. (1997) explicitly showed for copper that the grain boundary mobility does not differ for curvature-driven growth and strain-induced growth.

The next step in our derivation of transformation kinetics is to specify the reduction in dislocation density with time due to recovery. Typically, the rate of change in dislocation density is proportional to some positive power of dislocation density (e.g., annihilation requires encounters of dislocations, the number of encounters is the higher the higher their density; see for example Nes, 1995; Liu and Evans, 1997)

$\dot{\rho} \propto \rho^{p}$.

For first $(p=1)$ and second $(p=2)$ order reaction kinetics, integration yields specifically

$\rho(t)=\rho_{0}\left\{\begin{array}{c}\exp (-B t) \text { for } p=1 \\ \frac{1}{1+K \rho_{0} t} \text { for } p=2\end{array}\right.$,

when choosing $t_{0}=0$ for convenience. The two reaction constants reflect the intrinsic thermal activation of the ratecontrolling recovery process, i.e., $B=B_{0} \exp \left(-H_{\rho} / R T\right)$ 
and $K=K_{0} \exp \left(-H_{\rho} / R T\right)$. The relative extended volume calculates as

$X^{\text {ext }}=\frac{V_{\text {trans }}^{\text {ext }}}{V}=\frac{4}{3} \pi \frac{N}{V}\left(\chi m_{\mathrm{gb}} \mu b^{2}\right)^{3} \rho_{0}^{3}\left\{\begin{array}{c}\left(\int_{0}^{t} \exp (-B \tau) \mathrm{d} \tau\right)^{3} \text { for } p=1 \\ \left(\int_{0}^{t} \frac{\mathrm{d} \tau}{1+K \rho_{0} \tau}\right)^{3} \text { for } p=2\end{array}\right.$

and upon integration one finds the transformation to proceed according to

$X_{V}(t)=1-\left\{\begin{array}{c}\exp \left\{-\frac{A \rho_{0}^{3}}{B^{3}}[1-\exp (-B t)]^{3}\right\} \text { for } p=1 \\ \exp \left\{-\frac{A}{K^{3}}\left[\ln \left(1+K \rho_{0} t\right)\right]^{3}\right\} \text { for } p=2\end{array}\right.$

where we introduced $A=4 \pi \eta\left(\chi m_{\mathrm{gb}} \mu b^{2}\right)^{3} / 3$ with the nucleus density $\eta=N / V$.

In contrast to the classical JMAK theory the transformed volume may reach a limit of

$\lim _{t \rightarrow \infty} X_{V}(t)=1-\exp \left\{-\frac{A \rho_{0}^{3}}{B^{3}}\right\}$ for $p=1$

when the driving force is lost due to recovery before the transformation came to completion (Fig. 14). The secondorder reaction kinetics for recovery don't show this limit in our simple model but such behavior would arise if the model were extended by explicit finite dislocation densities for the recrystallized grains and the original grains. Substantial transformation occurs in a rather limited window of about one order of magnitude in dimensionless time. The associated characteristic transformation time is $t_{\mathrm{rec}} \sim 1 / A^{1 / 3} \rho_{0}$ for first and second-order kinetics. In the range of measurable percentages (1 to $100 \%$ ), Eqs. (10) either represent standard JMAK time dependence with a power of 3 leading to completion of transformation or lower and time-dependent exponents and stagnation of transformation before completion.

The effective Avrami parameters can be determined according to

$$
\begin{aligned}
n^{\prime} & =\frac{d}{d \ln t} \ln \left[\ln \left(\frac{1}{1-X_{V}(t)}\right)\right] \text { and } \\
Q^{\prime} & =-R \frac{d}{d(1 / T)} \ln \left[\ln \left(\frac{1}{1-X_{V}(t)}\right)\right]
\end{aligned}
$$

After algebraic manipulation, we find the exponent as

$$
n^{\prime}=\left\{\begin{array}{c}
\frac{3 B t}{\exp (B t)-1} \text { for } p=1 \\
\frac{3}{\ln \left(1+K \rho_{0} t\right)} \frac{K \rho_{0} t}{1+K \rho_{0} t} \text { for } p=2
\end{array}\right.
$$

and the activation energy as

$$
Q^{\prime}=3 H_{\mathrm{gg}}+\left(n^{\prime}-3\right) H_{\rho} \text { for } p=1,2
$$

assuming that the temperature dependence of the diffusion coefficient, i.e., $D \propto \exp \left(-H_{\mathrm{gg}} / R T\right)$ dominates the temperature dependence of the grain boundary mobility $m_{\mathrm{gb}}$. Initially, the change in growth rate is negligible and thus the classic Avrami parameters, an effective exponent of 3 and an effective activation energy of $3 H_{\mathrm{gg}}$, are found. With increasing time recovery becomes rate-relevant. The effective exponent decreases from 3 to 0 , for either order but secondorder kinetics yields a very slow decrease towards the end of the transformation process (Fig. 15a). The effective activation energy is ultimately given by the difference $3\left(H_{\mathrm{gg}}-H_{\rho}\right)$ (Fig. 15a). Thus, even for a very simple nucleation scenario as considered here (site saturation), effective Avrami parameters can be significantly time dependent when the driving force for growth exhibits a temporal evolution. Thus, small Avrami exponents do not necessarily indicate a low dimensionality of growth in the context of recrystallization. Effective activation energies are not easily interpreted either, owing to the two fundamental thermally activated processes that contribute to the kinetics of transformation, boundary migration and recovery.

\subsection{Quantitative analysis}

Thanks to the large number of studies on various aspects of the kinetics of deformation and recovery processes operative in olivine aggregates, one can actually attempt a quantitative analysis of the extended Avrami equation presented above. Instead of performing a numerical parameter search by an inversion procedure or the like, we rather investigate the basic relations among the involved model parameters and their general capability of modelling our observations. This strategy is motivated by the significant non-linearity of the multiparameter problem. The questions that we want to answer are (1) which requirements are posed on the involved kinetics parameters for model predictions to be in accord with our basic observations and (2) are these requirements compatible with currently available constraints on the involved parameters.

Our basic observation is the combined occurrence of effective Avrami parameters, $n^{\prime} \sim 1$ and $Q^{\prime} \sim 150 \pm 50 \mathrm{~kJ} \mathrm{~mol}^{-1}$, at transformation volume fractions of $X_{V} \sim 1$. We do face the issue here that volume ratios should probably be calculated relative to a volume representing deformed material rather than the entire sample volume but the distinction of reference is of subordinate relevance for our order of magnitude analysis. Solving $X_{V}\left(t_{0.1}\right)=0.1$ according to Eq. (10) for the time $t_{0.1}$ at which $10 \%$ transformation is reached and then analyzing $n^{\prime}\left(t_{0.1}\right)$ gives the following approximate constraints on the involved kinetics parameters:

$\frac{B}{A^{1 / 3} \rho_{0}} \simeq 0.84\left[\ln \left(\frac{1}{0.9}\right)\right]^{1 / 3} \simeq 1.8$ for $p=1$

and

$\frac{K}{A^{1 / 3}} \simeq 2.8\left[\ln \left(\frac{1}{0.9}\right)\right]^{1 / 3} \simeq 6.0$ for $p=2$. 
Furthermore, the effective activation energy provides a constraint on the relation between the activation enthalpies of grain boundary migration and recovery for $n^{\prime} \sim 1$,

$150 \mathrm{~kJ} \mathrm{~mol}^{-1} \sim 3 H_{\mathrm{gg}}-2 H_{\rho}$.

Finally, we require that for the investigated temperature range transformation actually occurs on laboratory timescales, i.e., the characteristic time of transformation ought to be

$t_{\text {rec }}=\frac{1}{A^{1 / 3} \rho_{0}} \sim 10^{5 \pm 1} \mathrm{~s}$

for first- and second-order kinetics.

The time of occurrence of transformation provides a direct constraint on the order of magnitude of grain-boundary mobility, i.e., $m_{\mathrm{gb}} \sim 3.4 \times 10^{-19 \pm 1} \mathrm{~m}^{4} \mathrm{~J}^{-1} \mathrm{~s}^{-1} / \chi$, when using the numerical values for the involved parameters as quoted in Table 3a This result seems to range at the lower end of (or actually falls short of) previously reported values for grainboundary mobility (Fig. 16a). Yet, apart from uncertainties in the estimates of nucleus density and initial dislocation density (lower than assumed values in either of the two lead to larger values in predicted grain-boundary mobility), drivingforce parameter $\chi$ as well as grain-boundary energy $\gamma$ play crucial roles in this comparison. Experimentally determined grain-growth constants have to be converted to mobility using a geometrical constant as well as grain-boundary energy, i.e., $m_{\mathrm{gb}}=k_{\mathrm{gg}} / 8 \gamma$. In particular the early phases of the transformation process may involve subgrains with interfacial energies orders of magnitude smaller than the assumed value of $1 \mathrm{~J} \mathrm{~m}^{-2}$ valid for large-angle grain boundaries. The mobility would be correspondingly larger.

Various constraints on grain boundary mobility in olivine aggregates are available. We focus on the grain growth law reported by Karato (1989), the range of mobility presented in the review by Evans et al. (2001), and a recent quantitative estimate derived from analyzing piezometric relations of olivine aggregates (Hackl and Renner, 2013). For the temperature range of our experiments a spread of $10^{-18}$ to $10^{-11} \mathrm{~m}^{4} \mathrm{~J}^{-1} \mathrm{~s}^{-1}$ is indicated (Fig. 16a). The corresponding activation enthalpies are $\sim 160 \mathrm{~kJ} \mathrm{~mol}^{-1}$ and 335 $\mathrm{kJ} \mathrm{mol}^{-1}$ from Karato (1989) and Hackl and Renner (2013), respectively. The latter is actually not a result of the analysis by Hackl and Renner (2013) but chosen relying on the consistency between diffusion creep rates and diffusion coefficients for Si-diffusion along grain boundaries in olaggregates (see Hirth and Kohlstedt, 2003). Toriumi (1982) reported $210 \pm 20 \mathrm{~kJ} \mathrm{~mol}^{-1}$ for grain boundary migration at isostatic stress conditions. The lack of quantitative consistency among the various constraints on grain boundary mobility likely stems from the involvement of pores that pin the boundaries. Considering experimental uncertainties and the uncertainties in transformation steps between the different measured parameters, it is thus fair to conclude that using the extended Avrami model with currently available constraints on grain boundary mobility does not lead to a conflict with the observed transformation kinetics.

Insertion of relation (18) into (15) and (16) yields constraints on the recovery kinetics

$B \simeq 1.78 \times 10^{-5 \mp 1} \mathrm{~s}^{-1}$ for $p=1$

$K \simeq \frac{6.0 \times 10^{-5 \mp 1} \mathrm{~s}^{-1}}{\rho_{0}} \sim 6.0 \times 10^{-20 \mp 1} \mathrm{~m}^{2} \mathrm{~s}^{-1}$ for $p=2^{.}$

The experimental studies on the recovery kinetics of olivine crystals unanimously find recovery to follow second-order kinetics, (i.e., $p=2$ in Eqs. (9) to (16)). The rate constants reported recently by Farla et al. (2011) deviate from earlier studies (Kohlstedt et al., 1980; Karato and Ogawa, 1982; Karato et al., 1993) by about two orders of magnitude at the conditions of the actual experiments performed to investigate the kinetics. Due to the difference in activation enthalpy this difference is diminished at the conditions of our experiments (Fig. 16b). The various studies yield a fairly consistent range for activation enthalpy of about 240 to $355 \mathrm{~kJ} \mathrm{~mol}^{-1}$ that may however be extended due to experimental uncertainties. These values are markedly lower than the value for diffusion of $\mathrm{Si}$ in olivine of $530 \mathrm{~kJ} \mathrm{~mol}^{-1}$ (Dohmen et al., 2002), relevant if dislocation climb was rate-controlling for the recovery processes (Karato et al., 1993). The requirement expressed by Eq. (19) falls right onto the experimentally derived parameters (Fig. 16b).

The constraint on effective activation energy (17) can be matched with a range of combinations of activation enthalpies (Fig. 17). Thus, the activation enthalpy relation does not provide an overly diagnostic means of identifying the likely relevant set of kinetics parameters. From an analysis of the literature values, we chose three pairs of enthalpies $H_{\mathrm{gg}}$ and $H_{\rho}$ as representative for further analyses. The effect of pressure differences among the various studies is subordinate compared to the quoted experimental uncertainties. An activation volume of $11 \mathrm{~cm}^{3} \mathrm{~mol}^{-1}$ as reported for recovery (Kohlstedt et al., 1980) corresponds to a change in activation enthalpy of 11 to $22 \mathrm{~kJ} \mathrm{~mol}^{-1}$ from ambient pressure to 1 or $2 \mathrm{GPa}$, respectively.

In summary, the constraints (15) to (18) for a match between our experimental observations and the proposed extended Avrami model can all be met in consistency with currently available quantitative estimates on the involved kinetics parameters. Out of the range of possible parameters we picked three sets and performed a forward calculation of the characteristics of the transformation progress (Fig. 18). According to the extended Avrami model, transformation in our experiments is characterized by effective parameters $n^{\prime}$ and $Q^{\prime}$ that vary significantly with time. 


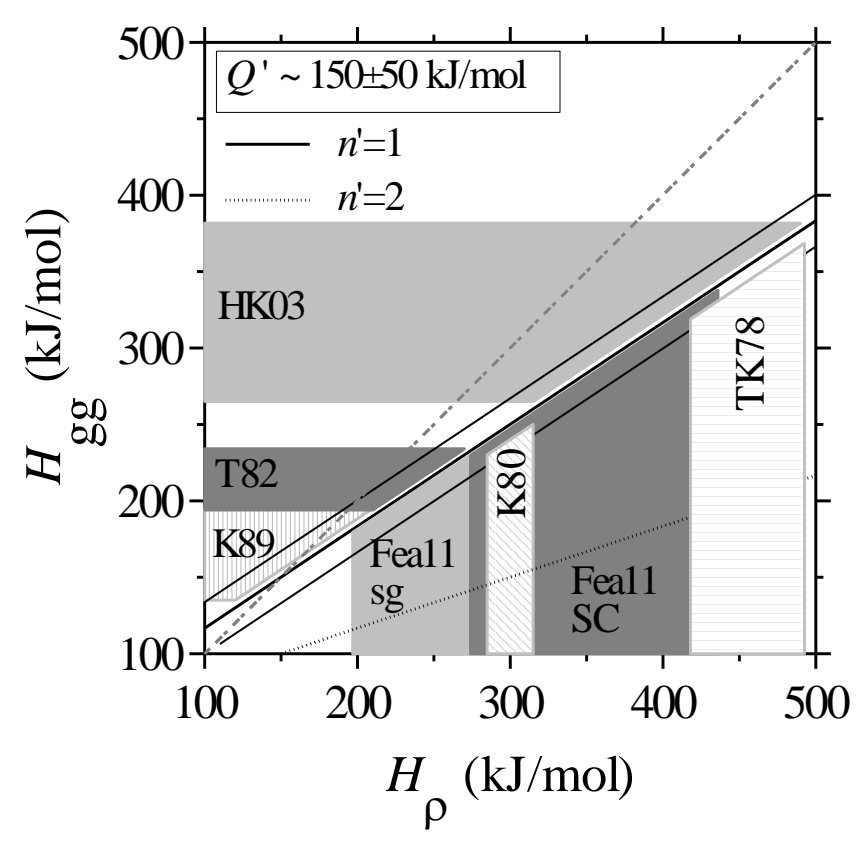

Fig. 17. Comparison of literature values for activation enthalpies of grain boundary mobility and dislocation recovery with the constraint provided by our experimental observations and the extended Avrami model (see Eq. (17)). Consistency is for example found pairing for example the migration enthalpy by Toriumi (1982) [T82] and the recovery enthalpy found by Farla et al. (2011) [Fea11] for samples prepared from sol gel (sg). From the various possibilities we pick three pairs of $H_{\mathrm{gg}}$ and $H_{\rho}$ values as representative: $\left(185 \mathrm{~kJ} \mathrm{~mol}^{-1}, 200 \mathrm{~kJ} \mathrm{~mol}^{-1}\right)$; $\left(230 \mathrm{~kJ} \mathrm{~mol}^{-1}, 270 \mathrm{~kJ} \mathrm{~mol}^{-1}\right)$; (335 kJ mol${ }^{-1}, 428 \mathrm{~kJ} \mathrm{~mol}^{-1}$ ). [K80: Karato (1980); K89: Karato (1989); HK02: Hirth and Kohlstedt (2003); TK78: Toriumi and Karato (1978)]

\subsection{Implications}

\subsubsection{Extrapolation to natural conditions}

The above-introduced transformation model is now extrapolated to $600^{\circ} \mathrm{C}$. A temperature of $600^{\circ} \mathrm{C}$ likely represents the lower base of the seismogenic zone for the oceanic lithosphere, as seismological studies found that the occurrence of earthquakes in the oceanic lithosphere appear to be limited in depth range by the $600^{\circ} \mathrm{C}$ isotherm (Abercrombie and Ekström, 2001, 2003; McKenzie et al., 2005). Consistently, evidence from naturally and experimentally deformed peridotite was presented that the transition from brittle to plastic deformation occurs at about $600^{\circ} \mathrm{C}$ (e.g., Jaroslow et al., 1996; Warren and Hirth, 2006; Boettcher et al., 2007; Druiventak et al., 2011).

Depending on the pair of activation enthalpies used, significant transformation will occur after tens to hundreds of years or it may last up to ten thousands of years until volume fractions of detectable size have undergone this specific microstructural transformation. The set of lowest en- thalpies gives the shortest duration since an extrapolation with them from experiments at higher temperatures causes the least change of the characteristic transformation times (tens of hours in the laboratory). Recovery kinetics has a modest effect on only one of the three considered scenarios of activation enthalpies (pair (1) in Figs. 17 and 19) for which also the fastest transformation is predicted. The other two scenarios essentially exhibit growth-limited transformation as indicated by the steep slope corresponding to $n^{\prime}=3$.

For the more rapid transformations, the concept of static recovery may become erroneous since stresses possibly do not fully relax on such short timescales but transformation will occur during creep with decreasing rate. The microfabrics found after our "kick and creep" experiments (core-andmantle-like microstructure with a large range in grain sizes and a weak to absent CPO not depending on the stress field) qualitatively show the same characteristics as the ones found after "kick and cook" experiments performed at the same temperature for the same duration. Quantitatively, the average size of new grains seems unaffected by the superposed creep, yet the area occupied by new grains is larger for dynamic recrystallization than for static recrystallization, probably caused by additional grain size reduction during early stages of creep.

Apart from the uncertainties in the used kinetics parameters, the extrapolation of our model may suffer from unresolved nucleation kinetics. While we argued against thermally activated nucleation we cannot exclude that early site saturation is a simplification that does not fully hold for natural conditions. Accounting for more complex nucleation scenarios as well as varying temperatures requires sophisticated numerical modelling (e.g., Kaminski and Ribe, 2001).

The presented extrapolation replaces our previous zero order attempt of using the effective activation energy of recrystallization of $150 \pm 50 \mathrm{~kJ} \mathrm{~mol}^{-1}$ to estimate the time reduction of our experiments in comparison to natural conditions (see Druiventak et al., 2012). Since two basic thermally activated processes, growth and recovery that are linked rather than independent, control recrystallization, the effective activation energy cannot be used for extrapolation but a detailed model that accounts for the link between the processes has to be employed. The extended model predicts, however, a dominance of the thermal activation of grain boundary migration, i.e., again a single activation enthalpy, rather than a time and temperature dependent effective activation energy, for the control of the transformation progress at temperatures of $600^{\circ} \mathrm{C}$ or lower. Therefore, the previous prediction and the current extrapolation coincide for the pair of activation enthalpies for which $H_{\mathrm{gg}}$ almost coincides with $Q^{\prime}$. This parameter set predicts the shortest characteristic times for transformation (tens of years) while the other two predict timescales that are larger by about one or more orders of magnitude. 

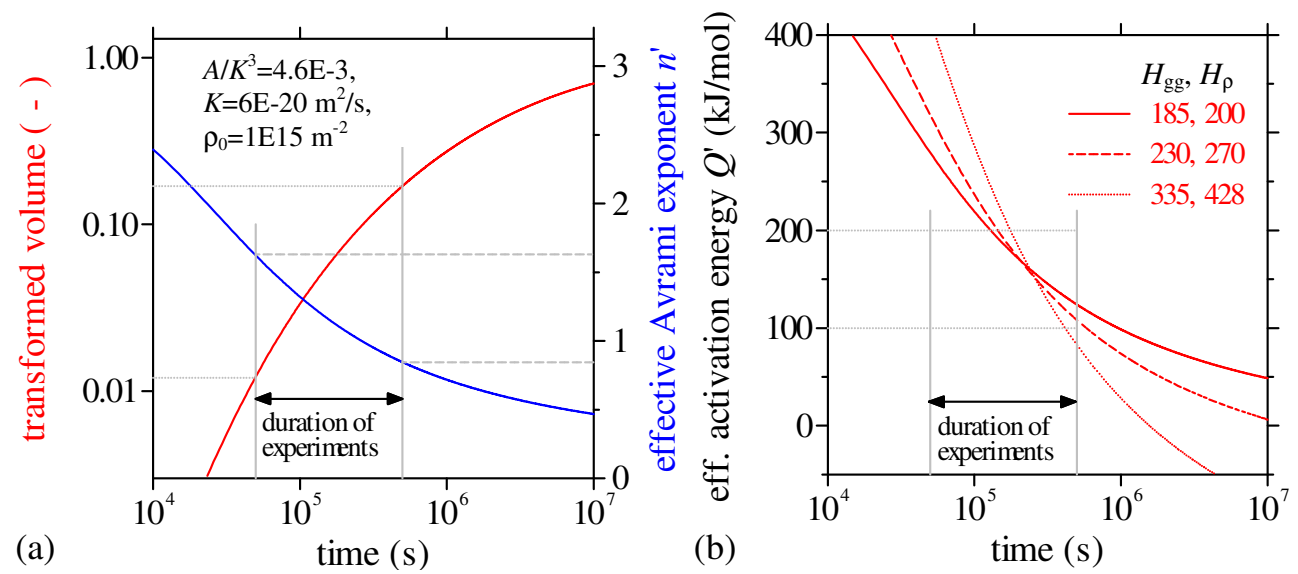

Fig. 18. (a) Transformation progress (left $y$ axis, red line) and effective Avrami exponent (right $y$ axis, blue line) and (b) effective activation energy as a function of time for second-order recovery kinetics and the kinetics parameters quoted in (a) that also apply to (b). The values of the used kinetics parameters were derived on the basis of Eq. (15) to (18) and are in fair agreement with experimental constraints on them (see Figs. 16 and 17 and text for comprehensive discussion). The horizontal and vertical lines document how indeed transformation volume and effective Avrami exponent match our experimental observations in the range of relevant experimental duration. In (b) results for the three pairs of activation enthalpies are shown that were identified from the compilation of literature values in Fig. 17.

\subsubsection{Diagnostic microstructures}

The most characteristic microstructural features after our "kick and cook" and "kick and creep" experiments are

1. the large range in grain size within one sample, where former highly damaged zones are still traceable by zones with relative finer grain sizes $(<10 \mu \mathrm{m})$ compared to areas beyond the highly damaged zones, even after annealing at high temperature $\left(\geq 900^{\circ} \mathrm{C}\right)$ and long isostatic annealing times $(\geq 70 \mathrm{~h})$.

2. Also the lack of a relation between crystal orientations and strain field (almost random CPO for recrystallized grains and host control for fragments) will remain stable in a prolonged low stress environment.

The area covered by new grains reached in samples from "kick and creep" experiments is by about a factor of two larger than the one reached in "kick and cook". But the observation of similar grain sizes, grain size distributions and orientation characteristics of new grains suggests that minor creep during relaxing stresses does not affect the microstructural identification potential of the characteristic sequence of high-stress deformation followed by recrystallization at decreasing stresses. Our experiments show that strain localization during initial high-stress low-temperature plasticity controls the recrystallization microstructure (grain size distribution and CPO) developed at isostatic or low stress conditions, leading to a modification and preservation of the initial heterogeneities. Thus, the combination of a large range in grain size and a CPO that is not related to the strain field are characteristics that allow recognizing a high-stress event in natural rocks even considering minor creep during stress relaxation and a prolonged thermal history at low stresses.
Investigations of shear zone peridotites of the Ivrea zone revealed microstructures with localized zones of new grains within or surrounding deformed porphyroclasts and a weak, unsystematic CPO (Druiventak et al., 2012; Matysiak and Trepmann, 2012) that are strikingly similar to the microstructures identified as diagnostic for high-stress deformation with subsequent annealing from our experiments, In peridotites from the Balmuccia complex of the Ivrea zone, these diagnostic microstructures occur together with pseudotachylytes, providing independent evidence of a nearby fault ruptured in a major earthquake.

\subsubsection{Reloading}

In nature, the reloading of seismically active faults may be relevant. The stress resolution in our "kick-cook-kick" and "cook-kick" experiments is probably not sufficient to assess the strength during the second deformation in great detail. Nevertheless, the mechanical data do not suggest a significant reduction in strength due to the presence of new grains, consistent with the microstructures found after "kick-cookkick" indicating that bulk deformation continues to be accommodated by deformation of the original grains (porphyroclasts). In fact, porphyroclasts in contact to aggregates of new grains (i.e., former highly damaged zones) appear preferentially deformed (Fig. 12c, d) suggesting that new grains are relatively stronger possibly owing to their smaller grain size. Brittle fracturing as well as low-temperature plasticity, the rheologies dominating deformation during the "kick" experiments (Druiventak et al., 2011), are known to result in inverse relationships between strength and grain size (e.g., Hall, 1951; Hirth, 1972; Petch, 1953; Frederich et al., 1990). Thus, repeated stress cycles (seismic events) presumably 


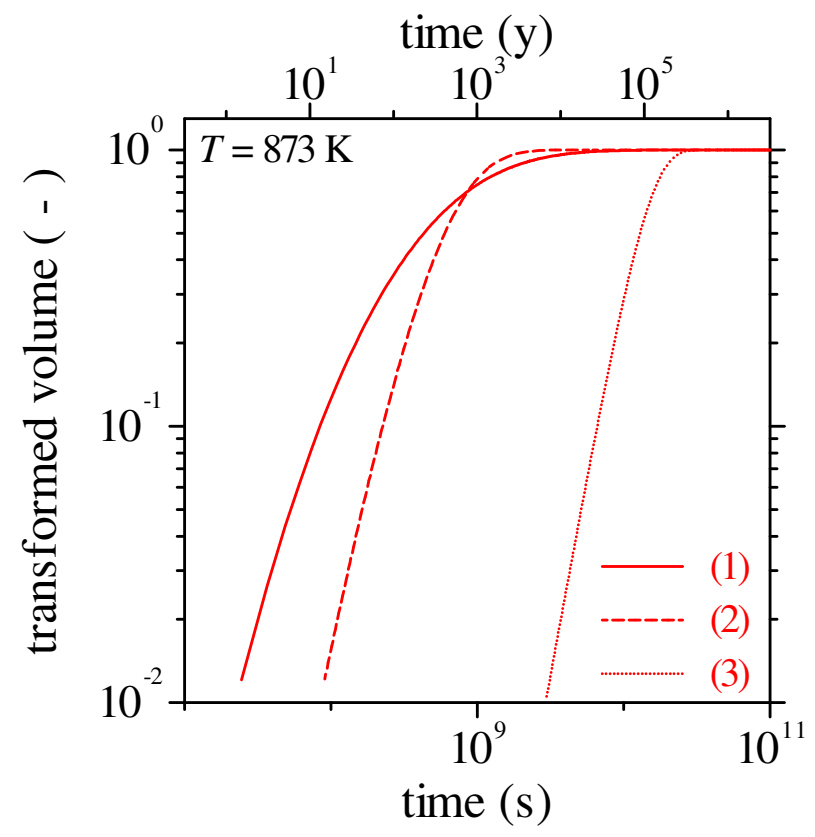

Fig. 19. Transformation progress extrapolated to $873 \mathrm{~K}$ for the three pairs of activation enthalpies identified from the compilation of literature values in Fig. 17:

(1) $H_{\mathrm{gg}}=185 \mathrm{~kJ} \mathrm{~mol}^{-1}, H_{\rho}=200 \mathrm{~kJ} \mathrm{~mol}^{-1}$,

$A / K^{3}=2.3 \times 10^{-2}, K=5.2 \times 10^{-23} \mathrm{~m}^{2} \mathrm{~s}^{-1}$

(2) $H_{\mathrm{gg}}=230 \mathrm{~kJ} \mathrm{~mol}^{-1}, H_{\rho}=270 \mathrm{~kJ} \mathrm{~mol}^{-1}$,

$A / K^{3}=3.2 \times 10^{-1}, K=4.4 \times 10^{-24} \mathrm{~m}^{2} \mathrm{~s}^{-1}$, and

(3) $H_{\mathrm{gg}}=335 \mathrm{~kJ} \mathrm{~mol}^{-1}, H_{\rho}=428 \mathrm{~kJ} \mathrm{~mol}^{-1}$,

$A / K^{3}=8.7 \times 10^{1}, K=1.7 \times 10^{-26} \mathrm{~m}^{2} \mathrm{~s}^{-1}$.

increase the volume of new grains that develop from deformed porphyroclasts during interseismic quiescence.

\section{Summary and conclusions}

During isostatic annealing of our "kick and cook" experiments, new grains develop in highly damaged zones (1) from cell structures (defect-free domains within crystalline material with high density of tangled dislocations), referred to as "recrystallized grains" and (2) from fragments of host grains with inherited dislocation density. The local density of new grains is controlled by the local strain accumulated by low-temperature plasticity and microfracturing during the "kick" experiment, leading to localized fine-grained aggregates of new grains tracing former highly damaged zones. At annealing temperatures $\geq 900^{\circ} \mathrm{C}$ and times $\geq 70 \mathrm{~h}$, the highly damaged zones are completely replaced by defectpoor new grains. Then, defect-free recrystallized grains are solely controlled by interfacial energy, pinning of boundaries by voids partially hampers further growth. Thus, recrystal- lized grains retain a small grain size of typically less than $10 \mu \mathrm{m}$ even after annealing at the highest explored temperature $\left(1100^{\circ} \mathrm{C}\right)$ and long annealing time (up to $144 \mathrm{~h}$ ). In contrast, strain-induced migration of boundaries between recrystallized grains and new grains originating from fragments with inherited defect-density can further proceed due to gradients in stored strain energy. Therefore, the area occupied by new grains exceeds the area of the original highly damaged zones after annealing at high temperatures for long durations. Former highly damaged zones are traceable by zones with relative finer grain sizes $(<10 \mu \mathrm{m})$ even after annealing at high temperature (up to $1100^{\circ} \mathrm{C}$ ) and long annealing time (up to $144 \mathrm{~h}$ ) without ("kick-cook") or with ("kickcreep") superposed stress. Thus, a high-stress (coseismic deformation) event is likely detectable in shear zone peridotites even after a prolonged thermal low-stress history with or without creep (postseismic creep) by a large range in grain sizes with localized fine-grained aggregates and weak to absent CPO that is not interpretable in terms of intracrystalline glide systems. When deforming an annealed rock volume again rapidly at high stresses ("kick-cook-kick"), strain is apparently concentrated in porphyroclasts surrounded by new grains, suggesting that repeated high-stress (seismic) events continuously increase the volume of new grains. Extrapolation of an extended Avrami-kinetics equation for which parameters were constrained from our results and previous kinetics studies suggests that the time-dependent transformation (i.e. replacement of deformed material by formation of new defect-poor grains) leading to the characteristic microstructure may develop in as little as some tens of years and not more than ten thousands of years at about $600^{\circ} \mathrm{C}$, i.e., approximate temperature condition at the base of the seismogenic zone in oceanic lithosphere. The characteristic heterogeneous microstructures are likely sufficiently stable to serve as an indicator of past seismic activity after a prolonged thermal low-stress history with minor creep and finally exhumation.

Acknowledgements. This study was generously funded by the German Science foundation, DFG-Collaborative Research Centre 526. We thank two anonymous referees for their constructive reviews.

Edited by: F. Rossetti 


\section{References}

Abercrombie, R. E. and Ekström, G.: Earthquake slip on oceanic transform faults, Nature, 410, 74-77, 2001.

Abercrombie, R. E. and Ekström, G.: A reassessment of the rupture characteristics of oceanic transform earthquakes, J. Geophys. Res., 108, 2225, 2003.

Atkinson, H. V.: Overview no. 65: Theories of normal grain growth in pure single phase systems, Acta Metall., 36, 469-491, 1988.

Avrami, M.: Kinetics of phase change. I General theory, The Journal of Chemical Physics, 7, 1103-1112, 1939.

Avrami, M.: Kinetics of phase change. II Transformation-time relations for random distribution of nuclei, The Journal of Chemical Physics, 8, 212-224, 1940.

Avrami, M.: Granulation, phase change, and microstructure kinetics of phase change. III, The Journal of Chemical Physics, 9, 177184, 1941.

Baluffi, R. W., Komen, Y., and Schober, T.: Electron microscope studies of grain boundary dislocation behaviour, Surf. Sci, 31, 68-103, 1972.

Ben-Zion, Y., and Lyakhovsky, V.: Analysis of aftershocks in a lithospheric model with seismogenic zone governed by damage rheology, Geophys. J. Int., 165, 197-210, 2006.

Ben-Zion, Y.: Collective behavior of earthquakes and faults: continuum-discrete transitions, progressive evolutionary changes, and different dynamic regimes, Rev. Geophys., 46, RG4006, doi:10.1029/2008RG000260, 2008.

Birtel, S. and Stöckhert, B.: Quartz veins record earthquake-related brittle failure and short term ductile flow in the deep crust, Tectonophysics, 457, 53-63, 2008.

Boettcher, M. S., Hirth, G., and Evans, B.: Olivine friction at the base of oceanic seismogenic zones, J. Geophys. Res., 112, B01205, doi:10.1029/2006JB004301, 2007.

Chopra, P. N. and Paterson, M. S.: The experimental deformation of dunite, Tectonophysics, 78, 453-473, 1981.

Christian, J. W.: The Theory of Transformations in Metals and Alloys: Part I + II, Elsevier Science Ltd, Oxford, 2002.

Cooper, R. F. and Kohlstedt, D. L.: Interfacial energies in the olivine-basalt system, Adv. Earth Planet. Sci, 12, 217-228, 1982.

Deer, W. A., Howie, R. A., and Zussman, J.: An introduction to the Rock-forming Minerals, Longman, Essex, 1, 528, 1992.

Dessa, J. X., Klingelhoefer, F., Graindorge, D., André, C., Permana, H., Gutscher, M. A., Chauhan, A., and Singh, S. C.: Megathrust earthquakes can nucleate in the forearc mantle: evidence from the 2004 Sumatra event, Geology, 37, doi:10.1130/G25653A, 2009.

Dohmen, R., Chakraborty, S., and Becker, H. W.: Si and O diffusion in olivine and implications for characterizing plastic flow in the mantle, Geophys. Res. Lett., 29, 2030, doi:10.1029/2002GL015480, 2002.

Drolet, J. and Galibois, A.: Altering the time cycle of heat treatment by preannealing prior to grain growth, Metall. Mater. Trans. B, 2, 53-64, 1971.

Druiventak, A., Trepmann, C. A., Renner, J., and Hanke, K.: Lowtemperature plasticity of olivine during high stress deformation of peridotite at lithospheric conditions - An experimental study, Earth Planet. Sci. Lett., 311, 199-211, 2011.

Druiventak, A., Matysiak, A., Renner, J., and Trepmann, C. A.: Kick-and-cook experiments on peridotite: simulating coseismic deformation and post-seismic creep, Terra Nova, 24, 62-69, 2012.
Drury, M. R. and Urai, J. L.: Deformation-related recrystallization processes, Tectonophysics, 172, 235-253, 1990.

Durinck, J., Devincre, B., Kubin, L., and Cordier, P.: Modeling the plastic deformation of olivine by dislocation dynamics simulations, Am. Min., 92, 1346-1357, 2007.

Duyster, J. and Stöckhert, B.: Grain boundary energies in olivine derived from natural microstructures, Contributions to Mineralogy and Petrology, 140, 567-576, 2001.

Ellis, S. and Stöckhert, B.: Elevated stresses and creep rates beneath the brittle-ductile transition caused by seismic faulting in the upper crust, J. Geophys. Res, 109, B05407, doi:10.1029/2003JB002744, 2004.

Evans, B. E., Renner, J. R., and Hirth, G. H.: A few remarks on the kinetics of static grain growth in rocks, Int. J. Earth Sci., 90, 88-103, 2001.

Farla, R., Kokkonen, H., Fitz Gerald, J., Barnhoorn, A., Faul, U., and Jackson, I.: Dislocation recovery in fine-grained polycrystalline olivine, Physics and Chemistry of Minerals, 38, 363-377, 2011.

Fitz Gerald, J. D. and Stünitz, H.: Deformation of granitoids at low metamorphic grade. I: Reactions and grain size reduction, Tectonophysics, 221, 269-297, 1993.

Fredrich, J. T., Evans, B., and Wong, T.-F.: Effect of grain size on brittle and semibrittle strength: Implications for micromechanical modelling of failure in compression, J. Geophys. Res., 95, 10907-10920, doi:10.1029/JB095iB07p10907, 1990.

Hackl, K. and Renner, J.: High-temperature deformation and recrystallization: a variational analysis and its application to olivine aggregates, J. Geophys. Res., 118, 943-967, doi:10.1002/jgrb.50125, 2013.

Hall, E. O.: The Deformation and Ageing of Mild Steel: III Discussion of Results, Proc. Phys. Soc. B., 64, 747-753, 1951.

Hirth, J.: The influence of grain boundaries on mechanical properties, Metall. Mater. Trans. B, 3, 3047-3067, 1972.

Hirth, G. and Kohlstedt, D.: Rheology of the upper mantle and the mantle wedge: a view from the experimentalists, in: Inside the Subduction Factory, edited by: Eiler, J., Geophys. Monogr., AGU, Washington, 83-105, 2003.

Hobbs, B. E.: Recrystallisation of single crystals of quartz, Tectonophysics 6, 353-401, 1968.

Holyoke III, C. W., and Kronenberg, A. K.: Accurate differential stress measurement using the molten salt cell and solid salt assemblies in the Griggs apparatus with applications to strength, piezometers and rheology, Tectonophysics, 494, 17-31, 2010.

Humphreys, F. J., and Hatherly, M.: Recrystallization and related annealing phenomena, 2 Edn., Elsevier Ltd, Oxford, 605 pp., 2004.

Jackson, I., Fitz Gerald, J. D., Faul, U. H., and Tan, B. H.: Grain-size-sensitive seismic wave attenuation in polycrystalline olivine, J. Geophys. Res.-Sol. Ea., 107, 2360, doi:10.1029/2001JB001225, 2002.

Jaroslow, G. E., Hirth, G., and Dick, H. J. B.: Abyssal peridotite mylonites: implications for grain-size sensitive flow and strain localization in the oceanic lithosphere, Tectonophysics, 256, 1737, 1996.

Johnson, W. A. and Mehl, R. F.: Reaction kinetics in processes of nucleation and growth, Trans. Am. Inst. Min. Metall. Engrs, 135, 416-458, 1939. 
Kaminski, É. and Ribe, N. M.: A kinematic model for recrystallization and texture development in olivine polycrystals, Earth Planet. Sci. Lett., 189, 253-267, 2001.

Karato, S. and Ogawa, M.: High-pressure recovery of olivine: implications for creep mechanisms and creep activation volume, Phys. Earth Planet. Int., 28, 102-117, 1982.

Karato, S., Rubie, D. C., and Yan, H.: Dislocation Recovery in Olivine Under Deep Upper Mantle Conditions: Implications for Creep and Diffusion, J. Geophys. Res., 98, 9761-9768, 1993.

Karato, S.: Grain growth kinetics in olivine aggregates, Tectonophysics, 168, 255-273, 1989.

Kempen, A. T. W., Sommer, F., and Mittemeijer, E. J.: The isothermal and isochronal kinetics of the crystallisation of bulk amorphous Pd40Cu30P20Ni10, Acta materialia, 50, 1319-1329, 2002.

Kohlstedt, D. L., Nichols, H. P. K., and Hornack, P.: The Effect of Pressure on the Rate of Dislocation Recovery in Olivine, J. Geophys. Res., 85, 3122-3130, 1980.

Küster, M., and Stöckhert, B.: High differential stress and sublithostatic pore fluid pressure in the ductile regime - microstructural evidence for short-term post-seismic creep in the Sesia Zone, Western Alps, Tectonophysics, 303, 263-277, 1999.

Liu, M. and Evans, B.: Dislocation recovery kinetics in singlecrystal calcite, J. Geophys. Res., 102, 24801-24809, 1997.

Liu, F., Sommer, F., and Mittemeijer, E. J.: An analytical model for isothermal and isochronal transformation kinetics, J. Mat. Sci., 39, 1621-1634, 2004.

Luo, H.: Effect of concurrent recovery on Avrami exponent of the softening kinetics after hot deformation, Mat. Sci. Engineer. A, 532, 44-49, 2012.

Matysiak, A. K. and Trepmann, C. A.: Crystal-plastic deformation and recrystallization of peridotite controlled by the seismic cycle, Tectonophysics, 530-531, 111-127, 2012.

McKenzie, D., Jackson, J., and Priestley, K.: Thermal structure of oceanic and continental lithosphere, Earth Planet. Sci. Lett., 233, 337-349, 2005.

Moghadam, R. H., Trepmann, C. A., Stöckhert, B., and Renner, J.: Rheology of synthetic omphacite aggregates at high pressure and high temperature, J. Petrology, 51, 92-1-945, 2010.

Nes, E.: Recovery revisited, Acta Metallurgica et Materialia, 43, 2189-2207, 1995.

Nicolas, A. and Poirier, J. P.: Crystalline Plasticity and Solid State Flow in Metamorphic Rocks, John Wiley, New York, 444 pp., 1976.

Nüchter, J.-A. and Stöckhert, B.: Vein quartz microfabrics indicating progressive evolution of fractures into cavities during postseismic creep in the middle crust, J. Struct. Geol., 29, 1445-1462, 2007.

Nüchter, J.-A. and Ellis, S.: Complex states of stress during the normal faulting seismic cycle: role of midcrustal postseismic creep, J. Geophys. Res., 115, B12411, doi:10.1029/2010JB007557, 2010.

Orzol, J., Stöckhert, B., Trepmann, C. A., and Rummel, F.: Experimental deformation of synthetic wet jadeite aggregates, J. Geophys. Res., 111, B06205, 2006.

Passchier, C. W. and Trouw, R. A. J.: Microtectonics, 2nd ed., Springer Verlag, Berlin-Heidelberg-New York, 2008.

Petch, N. J.: The cleavage strength of polycrystals, Journal of the Iron Steel Institute London, 174, 25-28, 1953.
Piazolo, S., Bestmann, M., Prior, D. J., and Spiers, C. J.: Temperature dependent grain boundary migration in deformed-thenannealed material: Observations from experimentally deformed synthetic rocksalt, Tectonophysics 427, 55-71, 2006.

Platt, J. P. and Behr, W. M.: Grainsize evolution in ductile shear zones: Implications for strain localization and the strength of the lithosphere, J. Struct. Geol., 33, 537-550, 2011 a.

Platt, J. P. and Behr, W. M.: Lithospheric shear zones as constant stress experiments, Geology, 39, 127-130, $2011 \mathrm{~b}$.

Renner, J., Zerbian, A., and Stöckhert, B.: Microstructures of synthetic polycrystalline coesite aggregates, The effect of pressure, temperature, and time, Lithos, 41, 169-184, 1997.

Rolandone, F., Bürgmann, R., and Nadeau, R. M.: The evolution of the seismic-aseismic transition during the earthquake cycle: constraints from the time-dependent depth distribution of aftershocks, Geophys. Res. Lett., 31, L23610, doi:10.1029/2004GL021379, 2004.

Rybacki, E., Renner, J., Konrad, K., Harbott, W., Rummel, F., and Stöckhert, B.: A Servohydraulically-controlled Deformation Apparatus for Rock Deformation under Conditions of Ultra-high Pressure Metamorphism, Pure Appl. Geophys., 152, 579-606, 1998.

Schaff, D. P., Bokelmann, G. H. R., Beroza, G. C., Waldhauser, F., and Ellsworth, W. L.: High-resolution image of Calaveras Fault seismicity, J. Geophys. Res.-Sol. Ea., 107, 2186, doi:10.1029/2001JB000633, 2002.

Scholz, C. H.: The mechanics of earthquakes and faulting. Cambridge University press, Cambridge, 2 Edn., 2002.

Shimizu, I.: Stress and temperature dependence of recrystallized grain size: a subgrain misorientation model, Geophys. Res. Lett., 25, 4237-4240, 1998.

Sibson, R. H.: Transient discontinuities in ductile shear zones, J. Struct. Geol., 2, 165-171, 1980.

Simpson, C. J. and Aust, K. T.: Grain boundary migration, Surface Science, 31, 479-497, 1972.

Singh, S. C., Carton, H., Tapponnier, P., Hananto, N. D., Chauhan, A. P. S., Hartoyo, D., Bayly, M., Moeljopranoto, S., Bunting, T., and Christie, P.: Seismic evidence for broken oceanic crust in the 2004 Sumatra earthquake epicentral region, Nat. Geosci., 1, 777-781, 2008.

Stipp, M. and Kunze, K.: Dynamic recrystallization near the brittleplastic transition in naturally and experimentally deformed quartz aggregates, Tectonophysics, 448, 77-97, 2008.

Stünitz, H., Fitz Gerald, J. D., and Tullis, J.: Dislocation generation, slip systems, and dynamic recrystallization in experimentally deformed plagioclase single crystals, Tectonophysics, 372, 215-233, 2003.

Toriumi, M. and Karato, S.: Experimental studies on the recovery process of deformed olivines and the mechanical state of the upper mantle, Tectonophysics, 49, 79-95, 1978.

Toriumi, M.: Grain boundary migration in olivine at atmospheric pressure, Phys. Earth Planet. Int., 30, 26-35, 1982.

Trepmann, C. A. and Stöckhert, B.: Mechanical twinning of jadeite - an indication of synseismic loading beneath the brittle-plastic transition, Int. J. Earth Sci., 90, 4-13, 2001.

Trepmann, C. A. and Stöckhert, B.: Cataclastic deformation of garnet: a record of synseismic loading and postseismic creep, J. Struct. Geol., 24, 1845-1856, 2002. 
Trepmann, C. A. and Stöckhert, B.: Quartz microstructures developed during non-steady state plastic flow at rapidly decaying stress and strain rate, J. Struct. Geol., 25, 2035-2051, 2003.

Trepmann, C. A., Stöckhert, B., Dorner, D., Moghadam, R. H., Küster, M., and Röller, K.: Simulating coseismic deformation of quartz in the middle crust and fabric evolution during postseismic stress relaxation - An experimental study, Tectonophysics, 442, 83-104, 2007.

Trepmann, C. A. and Stöckhert, B.: Short-wavelength undulatory extinction in quartz recording coseismic deformation in the middle crust - an experimental study, Solid Earth, 4, 263-276, doi:10.5194/se-4-263-2013, 2013.
Urai, J. L. and Humphreys, F. J.: A collection of time-lapse movies from transmitted light deformation experiments, in: Stress, Strain and Structure, A volume in honour of W. D. Means, edited by: Jessell, M. W. and Urai, J. L., Vol. 2, J. Virtual Explor., 2000.

Vandermeer, R. A., Jensen, D. J., and Woldt, E.: Grain boundary mobility during recrystallization of copper, Metall. Mater. Trans. A, 28, 749-754, 1997.

Warren, J. M. and Hirth, G.: Grain size sensitive deformation mechanisms in naturally deformed peridotites, Earth Planet. Sci. Lett., 248, 438-450, 2006. 